\title{
Lots of movement, little progress: A review of reptile home range literature
}

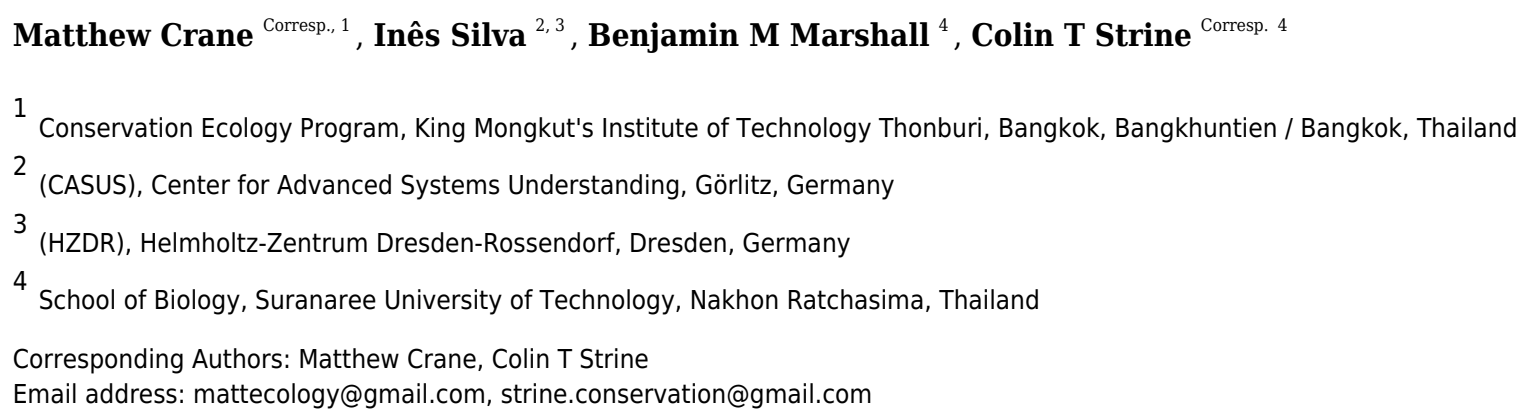

Reptiles are the most species-rich terrestrial vertebrate group with a broad diversity of life history traits. Biotelemetry is an essential methodology for studying reptiles as it compensates for several limitations when studying their natural history. We evaluated trends in terrestrial reptile spatial ecology studies focusing upon quantifying home ranges for the past twenty years. We assessed 290 English-language reptile home range studies published from 2000-2019 via a structured literature review investigating publications' study location, taxonomic group, methodology, reporting, and analytical techniques. Substantial biases remain in both location and taxonomic groups in the literature, with nearly half of all studies (45\%) originating from the USA. Snakes were most often studied, and crocodiles were least often studied, while testudines tended to have the greatest within study sample sizes. More than half of all studies lacked critical methodological details, limiting the number of studies for inclusion in future meta-analyses ( $55 \%$ of studies lacked information on individual tracking durations, and $51 \%$ lacked sufficient information on the number of times researchers recorded positions). Studies continue to rely on outdated methods to quantify space-use (including Minimum Convex Polygons and Kernel Density Estimators), often failing to report subtleties regarding decisions that have substantial impact on home range area estimates. Moving forward researchers can select a suite of appropriate analytical techniques tailored to their research question (dynamic Brownian Bridge Movement Models for within sample interpolation, and autocorrelated Kernel Density Estimators for beyond sample extrapolation). Only 1.4\% of all evaluated studies linked to available and usable telemetry data, further hindering scientific consensus. We ultimately implore herpetologists to adopt transparent reporting practices and make liberal use of open data platforms to maximize progress in the field of reptile spatial ecology. 


\section{Lots of movement, little progress: A review of reptile home 2 range literature}

4 Matt Crane $^{1^{*}}$, Inês Silva ${ }^{2,3}$, Benjamin Michael Marshall ${ }^{4}$, Colin Thomas Strine ${ }^{4^{*}}$

$5 \quad{ }^{1}$ Conservation Ecology Program, King Mongkut's University of Technology Thonburi, 49

6 Thakham, Bangkhuntien, Bangkok, 10150, Thailand

$7 \quad{ }^{2}$ Center for Advanced Systems Understanding (CASUS), 02826, Görlitz, Germany

$8{ }^{3}$ Helmholtz-Zentrum Dresden-Rossendorf (HZDR), 01328, Dresden, Germany

$9{ }^{4}$ School of Biology, Suranaree University of Technology, Nakhon Ratchasima, Thailand

10 Corresponding Author: Matt Crane ${ }^{1}$ and Colin Thomas Strine ${ }^{2}$

11 Email address: mattecology@gmail.com, strine.conservation@gmail.com 


\section{Abstract}

14 Reptiles are the most species-rich terrestrial vertebrate group with a broad diversity of life history traits.

15 Biotelemetry is an essential methodology for studying reptiles as it compensates for several limitations

16 when studying their natural history. We evaluated trends in terrestrial reptile spatial ecology studies

17 focusing upon quantifying home ranges for the past twenty years. We assessed 290 English-language

18 reptile home range studies published from 2000-2019 via a structured literature review investigating

19 publications' study location, taxonomic group, methodology, reporting, and analytical techniques.

20 Substantial biases remain in both location and taxonomic groups in the literature, with nearly half of all

21 studies (45\%) originating from the USA. Snakes were most often studied, and crocodiles were least often

22 studied, while testudines tended to have the greatest within study sample sizes. More than half of all

23 studies lacked critical methodological details, limiting the number of studies for inclusion in future meta-

24 analyses (55\% of studies lacked information on individual tracking durations, and $51 \%$ lacked sufficient

25 information on the number of times researchers recorded positions). Studies continue to rely on outdated

26 methods to quantify space-use (including Minimum Convex Polygons and Kernel Density Estimators),

27 often failing to report subtleties regarding decisions that have substantial impact on home range area

28 estimates. Moving forward researchers can select a suite of appropriate analytical techniques tailored to

29 their research question (dynamic Brownian Bridge Movement Models for within sample interpolation,

30 and autocorrelated Kernel Density Estimators for beyond sample extrapolation). Only 1.4\% of all

31 evaluated studies linked to available and usable telemetry data, further hindering scientific consensus. We

32 ultimately implore herpetologists to adopt transparent reporting practices and make liberal use of open

33 data platforms to maximize progress in the field of reptile spatial ecology.

\section{Introduction}

35

36

37

38

39

40

41

42

43

44

45

46

47

48

49

50

51
There are at least 11,242 described reptile species worldwide (Uetz, Freed \& Hošek, 2020; accessed 2020-04). Terrestrial reptiles typically have narrower niche requirements and smaller ranges than other vertebrates such as birds and mammals, leaving them increasingly susceptible to threats such as habitat loss or invasive species (Böhm et al., 2013). Nearly one in five reptilian species are threatened with extinction (17.2\%), and 14.4\% are Data Deficient (IUCN 2021; Böhm et al., 2013). Data deficiency in reptiles is higher than that of bird and mammal species $(0.5 \%$ and $14.2 \%$, respectively; Stattersfield, Bennun, \& Jenkins, 2004; Schipper et al., 2008); in particular for tropical reptiles and those with fossorial habits. Recent collapses of snake diversity have been reported with rippling effects to the ecosystem (Zipkin et al., 2020), but baseline data is often unavailable to properly evaluate these events and is likely understating the cascading effect of disappearing species (Roll et al., 2017). Many reptile species lack adequate baseline knowledge to inform conservation actions (Tingley, Meiri, Chapple, 2016; Etard, Morrill \& Newbold, 2020). Spatial ecology datasets can help fill these baseline knowledge gaps: revealing how animals react to human changes to the landscape (Tucker et al., 2018), informing species conservation status (Fraser et al., 2018), and offering key prior information to design population assessments (Gupta et al., 2019).

Efforts to collect baseline data are hindered by reptiles' natural history -often small, rare, and crypticlimiting detection probability. Telemetry studies can counteract low detection probability (or at least

Peer] reviewing PDF | (2020:12:56107:2:0:NEW 14 Jun 2021) 
52 provide baseline detection estimates; Boback et al., 2020), as we know exactly the number, identity, and

53 location of radio-marked individuals in the study site - with many potential applications (Refsnider et al.,

54 2011). By tracking animal movement, we gain valuable insight into habitat requirements, foraging

55 strategies, and behaviour (Kingsbury \& Robinson, 2016).

56 Radio-telemetry (VHF) is common in terrestrial reptile research, whereas the use of GPS and other automated telemetry technology in terrestrial reptiles is still relatively rare (e.g., Hart et al., 2015, Smith et

58

59

60

61

62

63

64

65

66

67

68

69

70

71

72

73

74

75

76

77

78

79

80

81

82

83

84

85

86

87

88

89

90

91

92

al., 2018) compared to other taxa (Joo et al., 2020). Using novel technologies and the resulting increased data volume in telemetry studies should also increase the analytical complexity and encourage greater uptake of more appropriate statistical methods. However, the uptake of modern techniques by practitioners within movement ecology has stagnated as the proportion of studies using movement-based area estimation methods is not matching the available software tools and methods (Joo et al., 2020).

The term "home range" is frequently and irrespectively applied to two distinct concepts: 1) the Burt (1943) home range definition, i.e., the area an animal uses for all of its lifetime activities, 2) within sample "space-use" (still commonly referred to as a "home range"), i.e., an area used by an animal throughout the study period duration. While both concepts have biological value, the chosen research question should govern choice of concept, and thus the space-use estimation methods researchers should use to answer their question. Researchers often use terms like "seasonal home range" to refer to animal space-use within the study period (Viana et al., 2018), delineating boundaries of interest based on season (Korbelová et al., 2016). Many studies improperly use the term home range (which by definition will include areas the animal used outside the study period, i.e., beyond-sample), when they intend to estimate short-term space-use of their animals (within-sample). Home ranges (in either of its definitions) and movement pattern data can help us understand population dynamics and habitat use, informing protected area size or policy processes (Metcalfe et al. 2015, Fraser et al. 2018), advocating for specific land-tenure systems (Johansson et al. 2016; Farhadinia et al. 2018), and recovery planning for threatened species (Parsons, 2016).

We treat reptile home range studies as any study intending to quantify space-use, regardless of whether the intent was to estimate areas used outside of the study or bounded by the study period. Initially, geometric methods such as the Minimum Convex Polygon (MCP) were the norm, but subsequently researchers have turned towards statistical techniques incorporating underlying probabilistic models, such as Kernel Density Estimators (KDE; Worton, 1989). The autocorrelated nature of movement data violates traditional KDEs assumptions led to the development of movement-based area estimation methods: autocorrelated KDEs (AKDEs; Fleming et al., 2015), and Brownian Bridge Movement Models (Horne et al., 2007; Kranstauber et al., 2012). Although researchers have continued to expand and develop analytical methods within movement and spatial ecology (Laver \& Kelly, 2008), the proportion of studies using movement-specific methods has not increased (Joo et al., 2020).

Macartney, Gregory, \& Larsen (1988) summarized the landscape of snake home range studies and suggested developing useful baseline data for comparative purposes requires longer-term studies and standardised data collection, analysis, and presentation. In 1990, a general review found most studies focused on mammals and used MCPs to estimate home ranges (Harris et al.,1990). By 2008, the same patterns were still present, with mammalian and ornithological home range studies most prevalent, and with 96 out of 141 studies still utilizing MCPs (51\% utilizing both MCPs and KDEs; Laver \& Kelly,

Peer) reviewing PDF | (2020:12:56107:2:0:NEW 14 Jun 2021) 
93

94

95

96

97

98

99

100

101

102

103

104

105

106

107

108

109

110

111

112

113

114

115

116

117

118

119

120

121

122

123

124

125

126

127

128

129

130

131

132

2008). Goldingay (2015) reviewed home-range studies for Australian terrestrial vertebrates between 2001-2012, and only 19\% out of 150 papers pertained to reptiles, even though Australia has over 860 native reptile species ( $39 \%$ of Australian's land species). As for home range estimators, MCPs appeared in $84 \%$ of these studies, followed by KDEs (45\%), illustrating a lack of methodology advancement despite a growing field. Taken together, previous reviews suggest the potential for shortfalls in reptile spatial studies and reliance on MCP or KDE methods. If trends in data missingness also apply (Etard et al., 2020), the shortfall in studies may be greatest in the tropics where reptiles are most diverse (Roll et al., 2017).

Here, we reviewed reptile telemetry literature to assess whether the field has shifted collection methods (e.g., GPS and satellite tags), and participated in the uptake of newer home range estimation techniques. We also sought to reveal underlying reptile home range study biases, both geographically and taxonomically, to determine future limitations in undertaking global syntheses and analyses. As most home range estimates are sensitive to study design and data collection protocol (e.g., number of locations and duration), we also evaluated reptile telemetry studies within the framework of open, reproducible, and comparable science, to determine the number of available datasets from our review. Finally, we make recommendations for improving reporting standards to aid in making reptile home range studies more broadly applicable and reproducible.

\section{Survey methodology}

We performed a comprehensive literature review by searching in Google Scholar, Web of Science, and Scopus on 30th of January, 2020 for articles relating to reptile spatial ecology using the terms ("reptile" OR "tortoise" OR "crocodile" OR "alligator" OR "snake" OR "lizard") AND ("home range" OR "homerange" OR "space use" OR "spatial ecology"). Following Haddaway et al., (2015) we only included the first 300 results from Google Scholar. We limited the search to papers from 2000-2019 published in peerreviewed journals, because we were interested in the changes/uptake of different computational home range methods (prior to 2000 researchers had to rely heavily on manual cartographic methods).

Our aim was solely terrestrial/semi-terrestrial reptile home range studies, so we excluded studies on marine species (e.g., sea turtles, sea snakes). However, we did include studies from semi-aquatic or typically range-limited to waterway species (e.g., crocodilians, freshwater turtles). We did not include marine species as they represent unique challenges and opportunities for modeling space-use such as 3D space use. We excluded studies lacking home range or space-use area estimates, such as those that only used movement measurements. As multiple field sampling techniques can generate home ranges, we defined our inclusion criteria as only studies using an attached telemetric device (e.g., VHF transmitters, GPS). We further excluded clear re-analyses of previously published datasets to avoid pseudoreplication. In these cases, we included only the oldest published article returned from the systematic search for review. However, we did include studies pooling previous data with newly collected data.

When studies included multiple species, we considered the overall methodology rather than for each species individually to avoid pseudoreplication. We only collected multiple values for a study's methodology if researchers used two different tracking devices (e.g., both VHF and GPS), as different tracking devices are subject to different limitations in data recording. We used the distinct biotransmitter type to review tracking protocols (e.g., sample frequency, number of locations) and trends in

Peer) reviewing PDF | (2020:12:56107:2:0:NEW 14 Jun 2021) 
133 biotransmitter selection (e.g., VHF vs GPS), but used study level effort to review geographic and 134 taxonomic patterns. From each included paper, we collected basic study information (country, year, 135 species, number of individuals tracked) as well as more detailed information about the data sampling 136 regime and home range estimation methods. To assess the field sampling protocols, we collected data 137 concerning the reporting of tracking duration, number of locations, and tracking frequency (number of 138 fixes per day) for studied individuals.

139

140

141

142

143

144

145

146

147

148

149

150

151

152

153

154

155

156

157

158

159

160

161

162

163

164

165

166

167

168

169

170

171

Regular temporal sampling is an assumption in several movement analyses, so we also identified whether studies conducted regular sampling. We defined two cases of regular temporal sampling: (1) sampling occurred at an equal hourly sampling rate (e.g., one fix every 2 hours, one fix every $15 \mathrm{~min}$ ), (2) individuals were located at least once per day consistently throughout the study (e.g., data with temporal resolution sufficient for subsetting to one location for every day the animal was tracked). We converted the reported tracking methodology into the number of tracks per day, recording both the minimum possible and maximum possible frequency. In cases where authors used ambiguous language (e.g., biweekly), or provided insufficient detail, we classified the tracking frequency as "not reported". We also documented whether the study used multiple regular tracking regimes (e.g., tracking once per day in the summer months, and only weekly during the winter).

We coded each article's adherence to two key repo4rting characteristics that can impact space-use and home range estimates: tracking time duration, and number of fixes. Tracking time duration differs from study duration and refers to the period of time over which researchers tracked an individual. In contrast, study duration is the overall study period, and thus represents a study-level characteristic, while tracking duration represents an individual-level characteristic. We scored articles on a scale of zero to three. For example, zero indicated reporting only study duration/study-level number of fixes (e.g., "...tracked individuals from 2018-01-01 to 2018-09-23..." or “...collected a total of 356 fixes...”) while failing to report the exact data quantity per individual (See Table 1 for details).

For each included study, we also recorded the method for estimating home range area. Kernel Density Estimation is a common technique but is highly dependent on the smoothing factor (h) selection method. To address this, we recorded the method used to determine the h-value for KDEs (when reported). We recorded whether the authors reported a movement metric based on time (e.g., mean daily displacement), as field sampling regime can also affect such metrics. Finally, we recorded if the study attempted to "validate" the home range estimation - i.e., included any form of analysis that assessed the relationship between number of locations and the home range area estimate (e.g., linear regressions, bootstrapped asymptotes). Each source was assigned a primary reviewer from the author team; however, any ambiguities in how a source should be coded was flagged and reviewed by all authors to remain consistent.

Table 1: Scoring category definitions for both number of location and study durations.

\section{Exploratory model}

We used a Logistic Bayesian Regression Model to explore the relationship between a reptile's body mass and the likelihood of them being studied. We used the log10 body mass data compiled by Meiri et al. (2021) and matched it to the study species within our literature search. We manually corrected 25 names 
172 that had changed or had been misspelt in our dataset. We inserted missing body mass data for

173 Platysternon megacephalum with results from Sung et al. (2014) suggesting an average body mass of 174 393.3g.

175 We used the resulting $\log 10$ body mass values to predict a binary of whether a species was studied 176 (Bernoulli distribution), and allowed both gradient and intercept to vary based on order: studied $\sim 1+$ $177 \log 10$ mass $+(1+$ order $\mid$ order $)$. We excluded orders Rhynchocephalia and Squamata (Amphisbaenia) 178 because of the low species richness and zero studied species respectively, and (sub-)families 179 Hydrophiinae, Dermochelyidae, and Cheloniidae as they are predominantly marine (final model $\mathrm{n}=$ 18011,037 species). We implemented weakly informative priors cauchy(location $=0.1$, scale $=3$ ) for the $181 \log 10$ mass coefficient and cauchy $($ location $=0$, scale $=1)$ for the standard deviation between orders.

182 We ran the model using four MCMC chains each with 5000 iterations and 2000 warmup, then thinned by 183 a factor of two. To achieve convergence, we increased the adaptive delta to 0.999 and maximum tree 184 depth of 15 . We assessed model convergence using $\hat{r}$ values $\sim 1$ and visual examinations of 185 autocorrelation and trace plots.

186

187

188

189

190

191

192

193

194

195

196

197

198

199

200

201

202

203

204

205

206

\section{Data and software availability}

We used R v.3.6.3 (R Core Team, 2020) and RStudio v.1.4.1029 (RStudio Team, 2020) to summarise all data. We summarised data with dplyr v.1.0.2 (Wickham et al., 2020), raster v.3.4.5 (Hijmans, 2020), forcats v.0.5.0 (Wickham, 2019a), reshape2 v.1.4.4 (Wickham, 2007), stringr v.1.4.0 (Wickham, 2019b), and tidybayes v.2.3.1 (Kay, 2020) packages. We ran Bayesian Regression Models using brms v.2.14.2 (Bürkner, 2017, 2018) and rstan v.2.21.2 (Stan Development Team, 2020). We visualised data with cowplot v.1.1.0 (Wilke, 2019), ggplot2 v.3.3.2 (Wickham, 2016), ggpubr v.0.4.0 (Kassambara, 2018), ggrepel v.0.8.2 (Slowikowski, 2018), ggridges v.0.5.2 (Wilke, 2018), ggtext v.0.1.1 (Wilke, 2020), and scico v.1.2.0 (Pedersen \& Crameri, 2018).

We have included all data, summary code, and model output at Zenodo: (http://doi.org/10.5281/zenodo.4303643). Data file "reptileHRReview_References.csv" includes the results of the stages of the literature review alongside article information; the data file "reptileHRReview_LiteratureReview.csv" contains the raw data from the literature review process; metadata file "reptileHRReview_Metadata.csv" includes full descriptions of all columns in both main data files. An additional file from Reptile Database (Uetz, Freed \& Hošek, 2020; accessed 2020-04) "reptileChecklist_2020_04.csv" includes the information used for genus- and clade-based summaries. We created the reptile diversity using Global Assessment of Reptile Distributions (GARD) data (representing $99 \%$ of reptile species' distributions at time of its publication [10,064 species]; Roll et al., 2017) and functionality from sf v.0.9.6 (Pebesma, 2018) and fasterize v.1.0.3 (Ross, 2020) packages. We counted terms used and produced the word cloud using pdftools v.2.3.1 (Ooms, 2019) and quanteda v.2.1.2 (Benoit et al., 2018). 


\section{Results}

\section{Data collection}

209 From 1,028 unique articles returned from the literature searches (Fig. S1), our exclusion criteria produced

210 a final sample of 290 reptile spatial ecology studies consisting of 302 tracking subsets (accounting for

211 multiple tracking protocols, i.e., GPS and VHF, within each study) involving 7,861 individual animals.

212 However, one study failed to report the number of animals tracked. The majority of studies used VHF

213 telemetry devices (277), with 22 using GPS, and a further three instances of ultrasonic or satellite

214 tracking. Regardless of the tracking method used, tracking frequency varied dramatically (Fig. 1): ranging

215 from 480 (24 if automated VHF is excluded) to 0.0328 tracks per day for VHF, and 144 to 0.143 per day

216 for GPS. In other words, tracking 0.0328 times per day is equivalent to tracking approximately once a

217 month (i.e., 1/30.5), and 0.143 times per day is the equivalent to tracking once per week (i.e., 1/7).

218 Eighty-eight tracking subsets (29.4\%) had consistent tracking frequencies throughout the study (i.e.,

219 minimum and maximum tracking frequency are the same, with no seasonal variation or multiple tracking

220

221

222 regimes), and 65 tracking subsets had a tracking frequency of at least once per day (i.e., minimum tracking frequency greater than one throughout the study period). The number of tracks/fixes per day was not always reported $(n=26 ; 9 \%)$, or reported ambiguous maximum and minimum number of tracks per

223

224 day (e.g., "bi-weekly", "at least"); this number increases to 78 tracking subsets that failed to clearly report one extreme of the tracking frequency. Such reporting is key when measurements of movement rate (or any metric that incorporates time) are calculated, and 190 out of 290 studies reported a movement metric.

Figure 1: Reported number of tracks per day. A) Density and boxplot plot showing the distribution of all per day. B) The variation per study between the maximum and minimum tracking frequencies, provided both are $<1$ per day. Both plots exclude all unreported tracking frequencies.

232

233

234

235

236

237

238

239

240

241

242

243

244
Despite the extensive field effort expended tracking 7,861 animals, we identified serious gaps in basic reporting that undermine understanding basic study characteristics. The gaps in reporting appear relatively consistent over the 20 years reviewed (Fig. 2). In addition to the 26 instances of incomplete tracking frequency data (Fig. 2A), 162 (56\%) studies provided very limited or missing descriptions of tracking duration (135 [47\%] scored 0, 27 [9\%] scored 1; Fig. 2B), and number of fixes obtained (95 [33\%] scored 0, 52 [18\%] scored 1, sum 147 [51\%]; Fig. 2B). Reporting standards of 2 and higher (i.e., likely sufficient to enable meta-analyses inclusion) were reached in 128 [44\%] studies for durations and 143 [49\%] for the number of fixes. Location reporting was further hindered by ambiguous terms, we found 34 different terms describing how many times an animal was tracked: studies largely used terms stemming from locat*, but even within a single study we often found multiple terms used to describe when researchers located animals (Fig. S2). Providing raw data could mitigate reporting deficiencies; however, we found only 24 [8\%] studies included links to external data and only 4 [1\% of all studies] of those links led to raw tracking data. 
246 Figure 2: Reporting scores over time. A) whether the study fully reported tracking frequency (complete in blue versus incomplete in red). B) \% of studies scoring 0 through 3 on location and duration reporting, where a score of 3

248 is the most complete reporting.

\section{Estimation methods}

250 Between 2000-2019 the number of studies per year increased from 6 in 2000 to 18 in 2019, with a low of 2514 in 2001 and a peak of 25 in 2017 (Fig. 3A). Minimum Convex Polygons (MCP) and Kernel Density 252 Estimations (KDE) use has dominated reptile home range studies for the past 20 years (272/290 studies; 253 Fig. 3B) and were present in over 75\% of studies each year (Fig. 3B). Frequently, studies include 254 estimations from both methods, and rarely use KDEs without including MCPs (Fig. S3). A minority of 255 studies $(\mathrm{n}=19)$ used "other" methods without pairing to estimations via MCPs and KDEs. These methods

256

257

258

259

260

261

262

263

264

265

266

267

268

269

270

271

272

273

\section{Geographic and taxonomic biases}

275

276

277

278

279 new, space-use estimation. a software. dearth of reptile home range papers (Fig. 4).

Figure 3: Changes in the field from 2000 to 2019. A) Number of articles over per year and the telemetry devices used: dark grey $=$ only VHF used, middle grey $=$ GPS was used exclusively or in conjunction with VHF, light grey $=$ other device used (ultrasonic and satellite). B) The percentage of studies using Minimum Convex Polygon (MCP), Kernel Density Estimations (KDE), both or other estimation methods. "Other" only includes studies that did not use either MCPs or KDEs. Lower text labels highlight the year select papers were published aiming to guide, or enable

Studies using MCPs largely made use of high \% contours (100\% and 95\%; Fig. S4). KDEs used a greater diversity of contour values ( 5 to $100 \%$ ), but with clear concentration towards $95 \%$ and $50 \%$. Studies more frequently ( $n=97 / 270$ studies using MCPs) failed to report the contour used with MCPs than other methods, potentially connected to the assumption that MCPs default to $100 \%$.

For studies using KDEs, we found 14 smoothing factor selection methods, but researchers primarily used Least Squares Cross-validation (LSCV; 73/159; Fig. S5). Similar to basic reporting, we show that 27 $(17.4 \%)$ studies failed to report a smoothing factor, either by omission or by only stating the "default" for

The United States of America is a clear hotspot where 133 of 290 studies were conducted. All other countries are dramatically lower ( $<8$ studies, 30 countries with a single study), with only Australia (35), Canada (22), and South Africa (12) breaking the trend. Despite high reptile diversity, Africa exhibited a

PeerJ reviewing PDF | (2020:12:56107:2:0:NEW 14 Jun 2021) 
280

281

282

283

284

285

286

287

288

289

290

291

292

293

294

295

296

297

298

299

300

301

302

303

304

305

306

307

308

309

310

311

312

313

314

315

316

Figure 4: Number of studies undertaken in each country. Colour scale is detailed in the insert density plot bottom right [blues indicating more studies, reds indicating fewer studies, grey indicating zero studies], showing the distribution of per country study counts. Count of studies is shown on a log scale to help differentiate between countries with fewer studies, a diverging colour scheme was selected to highlight the high-count outliers. Smaller territories are highlighted with a label denoting the number of studies. Insert map bottom left, shows the distribution of reptile species globally, ranging from zero species (black) to 182 species (yellow); the heatmap was generated using GARD data (Roll et al., 2017).

The 7,861 tracked individuals, 302 tracking subsets, and tracking subset sample sizes were not split evenly across the major clades of Crocodylia (mean individuals per subset $=11.1 \pm 1.62$ ), Serpentes (23.6 $\pm 1.71)$, Sauria (28.4 \pm 3.53$)$, and Testudines (35.4 \pm 6.80 ; Fig. 5). Serpentes was the most studied clade and with the most tracked individuals, whereas Crocodylia was the lowest. However, in terms of percentage of genera studied, Crocodylia leads with 44.4\% (4/9; Testudines 27/94, 28.7\%; Serpentes 40/522, 7.66\%; Sauria 28/564, 4.96\%).

Figure 5: Density and box plots showing the distribution of sample sizes (tracked individuals) per study by clade. Species names highlight the top two outlying sample sizes for clades other than Crocodylia.

Overall, of the 1,186 terrestrial reptile genera (Uetz, Freed \& Hošek, 2020; accessed 2020-04), 99 (8\%) have been tracked (but there are genera untrackable with current telemetry equipment, e.g., Amphisbaena and Ramphotyphlops). Two genera (Crotalus \& Gopherus) stand out having been studied 22 and 23 times (Fig. S6), whereas 45 genera had only a single study.

The Bayesian Regression Model successfully converged, revealing a very low base chance of a species being studied (and detected in the literature review): $0.06 \%$ ( $\mathrm{CrI} 0.02-0.18 \%)$. A species study chance increased at a population level with increased $\log 10$ body mass $\left(\beta_{\log 10 \text { mass }}=1.40,95 \%\right.$ median HDI CrI 1.23 - 1.58; Fig. 6); however, the overall model fit was poor (conditional R2 0.115, and marginal R2 0.113). While there were differences among the orders, the direction and magnitude of the differences was neither unambiguous nor large (Credible intervals all overlapped zero).

Figure 6: Fitted model values split by group effect of order, flanked top and below by the distribution of studied and unstudied species $\log 10$ body mass (jittered on the y-axis).

\section{Discussion}

We identified key issues limiting study comparability. Study design decisions regarding tracking frequency and duration are critical considerations when attempting to produce biologically relevant spaceuse estimates (Girard et al., 2002; Börger et al., 2006; Silva et al., 2020). These decisions determine total individual sampling effort; an individual with 12 locations over a single day is unequal to one with 12 locations over an entire year. Reporting solely the study duration (e.g., stating that tracking occurred between $\mathrm{X}$ and $\mathrm{Y}$ date) would then obscure individual variation - further hindering our ability to generalise across the study population. By reporting at the individual level, researchers can highlight

Peer] reviewing PDF | (2020:12:56107:2:0:NEW 14 Jun 2021) 
317 potential sources of heterogeneity between studies (e.g., tracking an animal once every week while

318 tracking others twice a week would hinder daily movement comparisons) (Alexander \& Maritz, 2015;

319 Riotte-Lambert \& Matthiopoulos, 2019). As we found a wide range of tracking frequencies throughout

320 reptile spatial ecology studies (and gaps in reporting), it limits our ability to conduct large inter-study

321 comparisons and undermines inter-study comparison validity.

322 Our review also reveals major biases in the study of reptile home ranges. Geographically, nearly $50 \%$ of

323

324

325

326

327

328

329

330

331

332

333

334

335

336

337

338

339

340

341

342

343

344

345

346

347

348

349

350

351

352

353

354

355

356

357

358 studies originated from a single country, the United States of America. We found a stark mismatch between reptile diversity and reptile home range study locations (Roll et al., 2017), reflecting similar gaps seen in reptile abundance studies (Doherty et al., 2020); in particular, the Middle East and Central Africa. Taxonomically, we observed less severe biases, but should still be considered in evaluating the patterns in the available data. Only $8 \%$ of genera have been studied and a relatively small number of genera dominate the available reptile spatial ecology data (e.g., Gopherus, Crotalus, Pituophis). Although the model fit was poor, our results show a greater chance that larger (by log10 mass) species are studied. The more frequent tracking of larger species likely stems from limitations surrounding biotelemetry device size to body mass ratio, and attachment/implantation methods required to track species with fossorial and arboreal habits. Efforts to synthesise reptile home range or movement must recognise that any results may be biased towards patterns in larger temperate western hemisphere species, rather than global trends. Global syntheses may be inhibited by the drastic differences in seasonal climate between well-studied temperate areas and neglected tropical regions, which is likely key to reptiles as ectotherms (Shine and Madsen, 1996). If the exceptional value and extent of reptile diversity in tropical areas (de Miranda, 2017; Roll et al., 2017) is underappreciated due to lack of data or representation, global conservation strategies may inadvertently tailor to larger temperate western hemisphere species.

Many of the issues that we revealed in the reptile spatial ecology literature can be mitigated with greater transparency, adopting open science and reproducible analyses (i.e., code-based analysis avoiding language ambiguities by comprising, and describing, the exact analytical procedure performed; Ince, Hatton \& Graham-Cumming, 2012; Archmiller et al., 2020). Open science presents a vital resource for replication efforts and can facilitate better meta-analyses. It also benefits the original researchers by increasing citations, boosting publication chances, and creating more potential collaborations (Piwowar \& Vision, 2013; Markowetz, 2015; Allen \& Mehler, 2018). The disparity between reptile data and other taxa on MoveBank (a prominent movement data repository) re-emphasizes our review findings. When searching either "reptilia" or "reptile", 24 reptile studies have available movement data on MoveBank as of 2020-02-12, and only 11 of those studies focus on terrestrial species out of over 6,000 available studies. Ecology journals (and herpetology journals especially; Marshall \& Strine, 2020) should redouble efforts to enforce data availability statements (Roche et al., 2015) and counteract the reluctance to biotelemetry data sharing expressed by late career researchers (Campbell et al., 2019), making data availability the default and refusing to accept "on request" statements (Aalbersberg et al., 2018). K'[ Researchers can make use of free data repositories (movement specific like MoveBank, or generic like Zenodo or OSF) to ease this process. We hope the opening of reptile movement data can facilitate broader studies similar to those undertaken in avian and mammalian fields (e.g., Tucker et al., 2019; Noonan et al., 2020).

Researchers often justify using KDEs and/or MCPs to compare with the wider reptile spatial ecology literature. However, methodological choices in reptile space-use studies hinder inter-study comparisons,

Peer] reviewing PDF | (2020:12:56107:2:0:NEW 14 Jun 2021) 
359

360

361

362

363

364

365

366

367

368

369

370

371

372

373

374

375

376

377

378

379

380

381

382

383

384

385

386

387

388

389

390

391

392

393

394

395

396

397

as KDEs and MCPs are sensitive to differences in sampling effort (e.g., number of locations, tracking duration and frequency) (Mitchell, White, \& Arnold, 2019; Silva et al., 2020). Reptile studies also used a wide range of smoothing factors for KDEs, which can also result in considerable home range over- or underestimations (Bauder et al., 2015; Silva et al., 2020). For example, two widely used smoothing factors, href and LSCV, produce dramatically different area estimations. Failure to report or account for smoothing factors is thus a major concern, as it would significantly alter meta-analysis patterns. Although Row \& Blouin-Demers (2006) suggested MCPs over KDEs for home range size comparisons across groups or time periods, MCP and KDE comparability is unreliable rendering their use generally inappropriate for most ecological studies (Nilsen, Pedersen, \& Linnell, 2008; Silva et al., 2020).

There is a growing body of work demonstrating the versatility of newer analytical methods (Noonan et al., 2018), and how they can be applied to the coarser resolution radio-telemetry data and the particulars of reptile movement (e.g., zero-inflated step lengths arising from long and frequent periods when the animal is stationary; Averill-Murray, Fleming, \& Riedle, 2020; Hromada et al., 2020; Silva et al., 2020). Reptile spatial ecology so far has largely failed to capitalise on the wealth of analytical options available, namely integrating movement information explicitly into estimations of space-use. Unlike traditional estimation methods (KDEs and MCPs), movement-based area estimation models do not operate under the assumptions breached by tracking data (independence of points) and guard better against under- and overestimation (Fleming \& Calabrese, 2017; Silva et al., 2020). One of the common solutions to autocorrelation is the thinning of data; this procedure is inherently wasteful and inefficient, defeating the purpose of collecting high temporal-resolution data and reducing the biological relevance of telemetry datasets (Fleming et al., 2015; Calabrese et al., 2020). With low temporal-resolution data (typical of VHF data), analytic approaches will not necessarily reveal the correct home range patterns and need to be applied with caution; in these cases, it may be necessary to reconsider the research questions or reevaluate study design for additional data collection. However, low sample sizes do not immediately exclude the use of newer methods; although typically designed to handle high volumes of data, AKDE will account for low sample sizes and can be used in conjugation with VHF data to obtain home range area estimates (Fleming et al. 2019). Similarly, dBBMMs can estimate movement pathways with lowvolume VHF reptile data (Silva et al. 2020).

Conceptualising home range as within sample versus beyond sample space-use requires distinguishing between occurrence distribution versus range distribution methods (Fleming et al., 2015; Horne et al., 2019; Fig. 7). While occurrence distributions (e.g., dBBMMs) allow us to answer research questions regarding the movement trajectory of an animal (and its confidence region), range distributions (e.g., AKDEs) consider the processes underlying animal movements and long-term space-use (Horne et al., 2019). Some research questions investigated in the reptile home range literature are actually targeting within sample space-use, requiring no extrapolation beyond the sampling period. In many cases, the sampling duration was too short to confidently identify range stability, which is a prerequisite for beyond sample home range estimates. To help unify the terminology used in reptile spatial ecology studies we draw attention to definitions from existing literature and reiterate them in Figure 7. 
398

399

400

401

402

403

404

405

406

407

408

409

410

411

412

413

414

415

416

417

418

419

420

421

422

423

424

425

426

427

428

429

430

431

432

433

434

435

436

437

438

439

Figure 7: A breakdown of the two complimentary conceptualisations of animal space-use. Displayed alongside are examples of the $99 \%$ contour derived from dynamic Brownian Bridge Movement Models (Kranstauber, Smolla \& Scharf, 2016) and autocorrelated Kernel Density Estimators (Calabrese, Fleming \& Gurarie, 2016; Fleming \& Calabrese, 2020). Data used is from Marshall et al. (2020) and can be found in Supp File 4.

Ambiguous language further compounded reporting issues. Failing to report estimation methods (or reporting with ambiguous or ill-defined acronyms) and associated smoothing parameters completely undermines computational reproducibility and inter-study comparability. Relatively few studies failed to attempt reporting their tracking frequency; many of the 79 failures to determine minimum or maximum tracking frequency were a direct result of ambiguous language, such as using words with multiple definitions (e.g., "bi-weekly") or using imprecise summaries (e.g., "at least"). We also found semantic ambiguity when describing locations. Studies used a wide range of terms to refer to locations, relocations, fixes, datapoints, etc., yet are selecting contrasting or overlapping definitions for these terms. The key distinction for the definition of location is whether it refers each time researchers documented the animal's spatial position or whether it refers only to a unique spatial position (a movement from the previously recorded location) used by the study animal (often referred to as "relocations"). Standardising and unifying terminology is essential for creating widely useful methods and comparable databases (Schneider et al., 2019), when in doubt researchers can explicitly define how they are using a given term in the study.

Answering specific questions requires appropriate protocols and, to draw broad inferences among a single study, those protocols must remain consistent. Between study comparisons also require consistency (or at least clear reporting on inconsistencies). The compound effect of geographical, taxonomical, and methodological biases undermine robust generalisations when ignored. Recent macroecological investigations did not explicitly model key methodological variables which affect MCP and KDE home range area estimates (e.g., tracking duration, number of locations, KDE bandwidth selection) (Slavenko et al. 2016; Todd \& Nowakowski 2020). While the general patterns described in such studies (e.g., home range area increasing with body mass) likely remain unchanged, not explicitly accounting for varying tracking regimes and different estimation methods (or variation within single estimation method) may obscure more nuanced patterns or differences in space-use. However, both MCPs and KDEs should be avoided when comparing studies for global meta-analyses because of sensitivity to sampling design; whereas methods such as AKDEs explicitly account for movement data biases (Noonan et al, 2020).

Researchers should aim to explore the sensitivity of the estimations to researcher choices (Signer \& Fieberg, 2020), while ensuring that their method suits their question. Home range estimation is not always the correct tool to answer short-term space-use or movement-related questions. In these cases, methods such as step selection analysis (Avgar et al. 2016), state-space (Patterson et al. 2008) or hidden Markov models (McClintock \& Michelot 2018) are more appropriate to infer animal movement, behaviour, and resource selection from telemetry data (Hooten et al. 2017). These methods still benefit from accurate methodological reporting and from researchers adopting Open Science principles, as sampling design similarly impacts which methods can apply to a given dataset (Quick et al. 2019).

To facilitate detailed reporting of tracking datasets, we have supplied an example report based on an existing tracking dataset (Marshall et al., 2020; Supp. File 2). This example aims to provide a bare-bones foundation for transparent reporting of sample size, study duration, number of datapoints, as well as important aspects used to describe the tracking regime: namely plots that describe individual tracking

Peer] reviewing PDF | (2020:12:56107:2:0:NEW 14 Jun 2021) 
440 durations (while highlighting deviation from proposed tracking protocols), and distribution of time lags 441 between tracks (as a more complete way of describing a tracking regime and the tracking consistency).

442 We have supplied the code (as an .Rmd file, Supp. File 3) and data (as a .csv, Supp. File 4) used to 443 generate the report as supplementary material.

\section{Conclusion}

445 The past 20 years have seen a growing number of reptile home range studies and continued reliance on 446 traditional but outdated methods, Kernel Density Estimations (KDEs) and Minimum Convex Polygons 447 (MCPs), for home range and space-use estimations, despite the availability of more appropriate methods. 448 Scientific conventions can be slow to shift, and often require substantial interdisciplinary research to 449 move towards better alternatives (Smaldino \& O'Connor, 2020). We appeal to researchers focusing on 450 reptiles to engage with appropriate statistical methods and Open Science principles, thus maximising the 451 value of hard-won field data. The best way to facilitate broader engagement is to adopt more transparent 452 practices by sharing and fully reporting collected data. Increasing reproducibility and availability of 453 datasets allows researchers to explore beyond home range estimation. Ultimately, we need to match 454 potential research questions to sampling design and the appropriate statistical analyses, achieving a better 455 understanding of both animal movement behavior and their long-term spatial requirements.

456

\section{Acknowledgements}

458

459

460

461

462

463

464

465

466

467

468

469

470

471

We thank Suranaree University of Technology, Institute of Science and Institute of Research and Development for logistic support and facilitating our research. We also thank King Mongkut's University of Technology Thonburi for support and particularly the Petchra Pra Jom Klao Scholarship. Also, we thank Aubrey Alamshah for her patience and support during several intensive reviewing and writing gatherings. We thank Supunnee Potijun Strine for suffering through the loss of her husband during long writing weekends and for providing much-needed sustenance during these times.

\section{References}

Aalbersberg IJ, Appleyard T, Brookhart S, Carpenter T, Clarke M, Curry S, Dahl J, DeHaven AC, Eich E, Franko M, Freedman L, Graf C, Grant S, Hanson B, Joseph H, Kiermer V, Kramer B, Kraut A, Karn RK, Lee C, MacFarlane A, Martone M, Mayo-Wilson E, McNutt M, McPhail M, Mellor DT, Moher D, Mudditt A, Nosek BA, Orland B, Parker TH, Parsons M, Patterson M, Santos S, Shore C, Simons DJ, Spellman B, Spies JR, Spitzer M, Stodden V, Swaminathan S, Sweet D, Tsui A, Vazire S. 2018. Making Science Transparent By Default: Introducing the TOP Statement. OSF Preprints. DOI: 10.31219/osf.io/sm78t.

PeerJ reviewing PDF | (2020:12:56107:2:0:NEW 14 Jun 2021) 
472

473

474

475

476

477

478

479

480

481

482

483

484

485

486

487

488

489

490

491

492

493

494

495

496

497

498

499

500

501

502

503

504

505

506

507

508

509

510

Alexander GJ, Maritz B. 2015. Sampling interval affects the estimation of movement parameters in four species of African snakes: Sampling interval affects estimation of movement. Journal of Zoology 297:309-318. DOI: 10.1111/jzo.12280.

Allen CPG, Mehler DMA. 2018. Open Science challenges, benefits and tips in early career and beyond. PsyArXiv. DOI: 10.31234/osf.io/3czyt.

Archmiller AA, Johnson AD, Nolan J, Edwards M, Elliott LH, Ferguson JM, Iannarilli F, Vélez J, Vitense K, Johnson DH, Fieberg J. 2020. Computational Reproducibility in The Wildlife Society's Flagship Journals. The Journal of Wildlife Management:jwmg.21855. DOI: 10.1002/jwmg.21855.

Averill-Murray RC, Fleming CH, Riedle JD. 2020. Reptile home ranges revisited: a case study of space use of Sonoran Desert tortoises (Gopherus morafkai). Herpetological Conservation and Biology $15(2), 253-271$.

Avgar T, Potts JR, Lewis MA, Boyce MS. 2016. Integrated step selection analysis: Bridging the gap between resource selection and animal movement. Methods in Ecology and Evolution, 7(5), 619-630. https ://doi.org/10.1111/2041-210X.12528

Bauder JM, Breininger DR, Bolt MR, Legare ML, Jenkins CL, McGarigal K. 2015. The role of the bandwidth matrix in influencing kernel home range estimates for snakes using VHF telemetry data. Wildlife Research, 42:437-453.

Benoit K, Watanabe K, Wang H, Nulty P, Obeng A, Müller S, Matsuo A. 2018. quanteda: An R package for the quantitative analysis of textual data. Journal of Open Source Software 3:774. DOI: $10.21105 /$ joss. 00774 .

Boback SM, Nafus MG, Yackel Adams AA, Reed RN. 2020. Use of visual surveys and radiotelemetry reveals sources of detection bias for a cryptic snake at low densities. Ecosphere 11(1), e03000.

Böhm M, Collen B, Baillie JEM, Bowles P, Chanson J, Cox N, Hammerson G, Hoffmann M, Livingstone SR, Ram M, Rhodin AGJ, Stuart SN, van Dijk PP, Young BE, Afuang LE, Aghasyan A, García A, Aguilar C, Ajtic R, Akarsu F, Alencar LRV, Allison A, Ananjeva N, Anderson S, Andrén C, Ariano-Sánchez D, Arredondo JC, Auliya M, Austin CC, Avci A, Baker PJ, Barreto-Lima AF, Barrio-Amorós CL, Basu D, Bates MF, Batistella A, Bauer A, Bennett D, Böhme W, Broadley D, Brown R, Burgess J, Captain A, Carreira S, Castañeda M del R, Castro F, Catenazzi A, CedeñoVázquez JR, Chapple DG, Cheylan M, Cisneros-Heredia DF, Cogalniceanu D, Cogger H, Corti C, Costa GC, Couper PJ, Courtney T, Crnobrnja-Isailovic J, Crochet P-A, Crother B, Cruz F, Daltry JC, Daniels RJR, Das I, de Silva A, Diesmos AC, Dirksen L, Doan TM, Dodd CK, Doody JS, Dorcas ME, Duarte de Barros Filho J, Egan VT, El Mouden EH, Embert D, Espinoza RE, Fallabrino A, Feng X, Feng Z-J, Fitzgerald L, Flores-Villela O, França FGR, Frost D, Gadsden H, Gamble T, Ganesh SR, Garcia MA, García-Pérez JE, Gatus J, Gaulke M, Geniez P, Georges A, Gerlach J, Goldberg S, Gonzalez J-CT, Gower DJ, Grant T, Greenbaum E, Grieco C, Guo P, Hamilton AM, Hare K, Hedges SB, Heideman N, Hilton-Taylor C, Hitchmough R, Hollingsworth B, Hutchinson M, Ineich I, Iverson J, Jaksic FM, Jenkins R, Joger U, Jose R, Kaska Y, Kaya U, Keogh JS, Köhler G, Kuchling G, Kumlutaş Y, Kwet A, La Marca E, Lamar

Peer] reviewing PDF | (2020:12:56107:2:0:NEW 14 Jun 2021) 
511

512

513

514

515

516

517

518

519

520

521

522

523

524

525

526

527

528

529

530

531

532

533

534

535

536

537

538

539

540

541

542

543

544

545

546

W, Lane A, Lardner B, Latta C, Latta G, Lau M, Lavin P, Lawson D, LeBreton M, Lehr E, Limpus D, Lipczynski N, Lobo AS, López-Luna MA, Luiselli L, Lukoschek V, Lundberg M, Lymberakis P, Macey R, Magnusson WE, Mahler DL, Malhotra A, Mariaux J, Maritz B, Marques OAV, Márquez R, Martins M, Masterson G, Mateo JA, Mathew R, Mathews N, Mayer G, McCranie JR, Measey GJ, Mendoza-Quijano F, Menegon M, Métrailler S, Milton DA, Montgomery C, Morato SAA, Mott T, Muñoz-Alonso A, Murphy J, Nguyen TQ, Nilson G, Nogueira C, Núñez H, Orlov N, Ota H, Ottenwalder J, Papenfuss T, Pasachnik S, Passos P, Pauwels OSG, Pérez-Buitrago N, Pérez-Mellado V, Pianka ER, Pleguezuelos J, Pollock C, Ponce-Campos P, Powell R, Pupin F, Quintero Díaz GE, Radder R, Ramer J, Rasmussen AR, Raxworthy C, Reynolds R, Richman N, Rico EL, Riservato E, Rivas G, da Rocha PLB, Rödel MO, Rodríguez Schettino L, Roosenburg WM, Ross JP, Sadek R, Sanders K, Santos-Barrera G, Schleich HH, Schmidt BR, Schmitz A, Sharifi M, Shea G, Shi H-T, Shine R, Sindaco R, Slimani T, Somaweera R, Spawls S, Stafford P, Stuebing R, Sweet S, Sy E, Temple HJ, Tognelli MF, Tolley K, Tolson PJ, Tuniyev B, Tuniyev S, Üzüm N, van Buurt G, Van Sluys M, Velasco A, Vences M, Veselý M, Vinke S, Vinke T, Vogel G, Vogrin M, Vogt RC, Wearn OR, Werner YL, Whiting MJ, Wiewandt T, Wilkinson J, Wilson B, Wren S, Zamin T, Zhou K, Zug G. 2013. The conservation status of the world's reptiles. Biological Conservation 157:372-385. DOI: 10.1016/j.biocon.2012.07.015.

Börger L, Franconi N, De Michele G, Gantz A, Meschi F, Manica A, Lovari S, Coulson T. 2006. Effects of sampling regime on the mean and variance of home range size estimates. Journal of Animal Ecology 75:1393-1405. DOI: 10.1111/j.1365-2656.2006.01164.x.

Bürkner P-C. 2017. brms: An R package for Bayesian multilevel models using Stan. Journal of Statistical Software 80:1-28. DOI: 10.18637/jss.v080.i01.

Bürkner P-C. 2018. Advanced Bayesian multilevel modeling with the R package brms. The R Journal 10:395-411. DOI: 10.32614/RJ-2018-017.

Burt WH. 1943. Territoriality and Home Range Concepts as Applied to Mammals. Journal of Mammalogy 24:346-352. DOI: 10.2307/1374834.

Calabrese JM, Fleming CH, Gurarie E. 2016. Ctmm: an R Package for Analyzing Animal Relocation Data As a Continuous-Time Stochastic Process. Methods in Ecology and Evolution 7:1124-1132. DOI: $10.1111 / 2041-210 X .12559$.

Calabrese JM, Fleming CH, Noonan MJ, Dong X. 2020. ctmmweb: A graphical user interface for autocorrelation-informed home range estimation. BioRxiv.

Campbell HA, Micheli-Campbell MA, Udyawer V. 2019. Early career researchers embrace data sharing. Trends in Ecology \& Evolution, 34(2), 95-98. DOI: 10.1016/j.tree.2018.11.010

de Miranda EB. 2017. The plight of reptiles as ecological actors in the tropics. Frontiers in Ecology and Evolution, 5:159. 
547 Doherty TS, Balouch S, Bell K, Burns TJ, Feldman A, Fist C, Garvey TF, Jessop TS, Meiri S, Driscoll

548

549

550

551

552

553

554

555

556

557

558

559

560

561

562

563

564

565

566

567

568

569

570

571

572

573

574

575

576

577

578

579

580

581
DA. 2020. Reptile responses to anthropogenic habitat modification: A global meta-analysis.

Global Ecology and Biogeography 29:1265-1279. DOI: 10.1111/geb.13091.

Etard A, Morrill S, Newbold T. 2020. Global gaps in trait data for terrestrial vertebrates. Global Ecology and Biogeography:geb.13184. DOI: 10.1111/geb.13184.

Farhadinia MS, Johnson PJ, Macdonald DW, Hunter LT. 2018. Anchoring and adjusting amidst humans: Ranging behavior of Persian leopards along the Iran-Turkmenistan borderland. PLoS One 13(5), p.e0196602. DOI: 10.1371/journal.pone.0196602

Fleming CH, Calabrese JM. 2017. A new kernel density estimator for accurate home-range and species-range area estimation. Methods in Ecology and Evolution 8(5), 571-579.

Fleming CH, Calabrese JM. 2020. ctmm: Continuous-Time Movement Modeling.

Fleming CH, Fagan WF, Mueller T, Olson KA, Leimgruber P, Calabrese JM. 2015. Rigorous home range estimation with movement data: a new autocorrelated kernel density estimator. Ecology 96(5), 1182-1188.

Fleming CH, Noonan MJ, Medici EP, Calabrese JM. 2019. Overcoming the challenge of small effective sample sizes in home-range estimation. Methods in Ecology and Evolution 10(10), 1679-1689.

Fraser KC, Davies KT, Davy CM, Ford AT, Flockhart DTT, Martins EG. 2018. Tracking the conservation promise of movement ecology. Frontiers in Ecology and Evolution 6:150. DOI: 10.3389/FEVO.2018.00150.

Girard I, Ouellet J-P, Courtois R, Dussault C, Breton L. 2002. Effects of Sampling Effort Based on GPS Telemetry on Home-Range Size Estimations. The Journal of Wildlife Management 66:1290. DOI: $10.2307 / 3802962$.

Goldingay RL. 2015. A review of home-range studies on Australian terrestrial vertebrates: adequacy of studies, testing of hypotheses, and relevance to conservation and international studies. Australian Journal of Zoology 63(2), 136-146.

Gupta A, Dilkina B, Morin DJ, Fuller AK, Royle JA, Sutherland C, Gomes CP. 2019. Reserve design to optimize functional connectivity and animal density. Conservation Biology 33(5), 1023-1034. DOI: $10.1111 /$ cobi.13369.

Hijmans RJ. 2020. raster: Geographic data analysis and modeling.

Haddaway NR, Collins AM, Coughlin D, Kirk S. 2015. The Role of Google Scholar in Evidence Reviews and Its Applicability to Grey Literature Searching. PLOS ONE 10:e138237. DOI: 10.1371/journal.pone.0138237.

Harris S, Cresswell WJ, Forde PG, Trewhella WJ, Woollard T, Wray S. 1990. Home-range analysis using radio-tracking data-a review of problems and techniques particularly as applied to the study of mammals. Mammal Review 20:97-123. DOI: 10.1111/j.1365-2907.1990.tb00106.x.

PeerJ reviewing PDF | (2020:12:56107:2:0:NEW 14 Jun 2021) 
582

583

584

585

586

587

588

589

590

591

592

593

594

595

596

597

598

599

600

601

602

603

604

605

606

607

608

609

610

611

612

613

614 Kranstauber B, Smolla M, Scharf AK. 2016. Package 'move'. DOI:

615 Florida, USA. Animal Biotelemetry 3:8. telemetry data. Boca Raton, FL: CRC Press. Ecology 88(9), 2354-2363. tortoise. Movement Ecology 8(1), 1-18. 488. DOI: $10.1038 /$ nature 10836. $<$ https://www.iucnredlist.org $>$ 10.1016/j.biocon.2016.08.034 movement ecology. arXiv preprint arXiv:2006.00110.

Kassambara A. 2018. ggpubr: "ggplot2" based publication ready plots. http://mjskay.github.io/tidybayes/>. Conservation: A Handbook of Techniques, 110. Animal Ecology 81(4), 738-746. 10.1371/journal.pone.0151984> License.

Hart KM, Cherkiss MS, Smith BJ, Mazzotti FJ, Fujisaki I, Snow RW, Dorcas ME. 2015. Home range, habitat use, and movement patterns of non-native Burmese pythons in Everglades National Park,

Hooten MB, Johnson DS, McClintock BT, Morales JM. 2017. Animal movement: Statistical models for

Horne JS, Garton EO, Krone SM, Lewis JS. 2007. Analyzing animal movements using Brownian bridges.

Horne EJS, Fieberg J, Börger L, Rachlow JL, Calabrese JM, Fleming CH. 2019. Animal Home Ranges. in Murray DL, Sandercock BK (Eds.). 2020. Population Ecology in Practice. John Wiley \& Sons.

Hromada SJ, Esque TC, Vandergast AG, Dutcher KE, Mitchell CI, Gray ME, Chang T, Dickson BG, Nussear KE. 2020. Using movement to inform conservation corridor design for Mojave desert

Ince DC, Hatton L, Graham-Cumming J. 2012. The case for open computer programs. Nature 482:485-

IUCN 2021. The IUCN Red List of Threatened Species. Version 2021-1. Accessed: 2021-04-10.

Johansson Ö, Rauset GR, Samelius G, McCarthy T, Andrén H, Tumursukh L, Mishra C. 2016. Land sharing is essential for snow leopard conservation. Biological Conservation 203, 1-7. DOI:

Joo R, Picardi S, Boone ME, Clay TA, Patrick SC, Romero-Romero VS, Basille M. 2020. A decade of

Kay M. 2020. tidybayes: Tidy Data and Geoms for Bayesian Models_. doi: 10.5281/zenodo.1308151

(URL: https://doi.org/10.5281/zenodo.1308151), R package version 2.1.1, <URL:

Kingsbury BA, Robinson NJ. 2016. Movement patterns and telemetry. Reptile Ecology and

Korbelová J, Hamšíková L., Maloň J, Válková L, Vorel A. (2016). Seasonal variation in the home range size of the Eurasian beaver: do patterns vary across habitats?. Mammal Research, 61(3), 243-253.

Kranstauber B, Kays R, LaPoint SD, Wikelski M, Safi K. 2012. A dynamic Brownian bridge movement model to estimate utilization distributions for heterogeneous animal movement. Journal of

Peer] reviewing PDF | (2020:12:56107:2:0:NEW 14 Jun 2021) 
616 Laver PN, Kelly MJ. 2008. A critical review of home range studies. The Journal of Wildlife Management $617 \quad 72(1), 290-298$.

618 Macartney JM, Gregory PT, Larsen KW. 1988. A tabular survey of data on movements and home ranges 619 of snakes. Journal of Herpetology 61-73.

620

621

622

623

624

625

626

627

628

629

630

631

632

633

634

635

636

637

638

639

640

641

642

643

644

645

646

647

648

649

650

651

652

Markowetz F. 2015. Five selfish reasons to work reproducibly. Genome Biology 16:274. DOI: 10.1186/s13059-015-0850-7.

Marshall BM, Strine CT. 2020. Make like a glass frog: In support of increased transparency in herpetology. OSF Preprints. DOI: 10.31219/osf.io/74frd.

Marshall BM, Crane M, Silva I, Strine CT, Jones MD, Hodges CW, Suwanwaree P, Artchawakom T, Waengsothorn S, Goode M. 2020. No room to roam: King Cobras reduce movement in agriculture. Movement Ecology 8:33. DOI: 10.1186/s40462-020-00219-5.

Meiri S, Murali G, Zimin A, Shak L, Itescu Y, Caetano G, Roll U. 2021. Different solutions lead to similar life history traits across the great divides of the amniote tree of life. Journal of Biological Research-Thessaloniki, 28(1), 1-17. DOI: 10.1186/s40709-021-00134-9

Metcalfe K, Vaughan G, Vaz S, Smith, RJ. 2015. Spatial, socio-economic, and ecological implications of incorporating minimum size constraints in marine protected area network design. Conservation Biology 29(6), 1615-1625. DOI: 10.1111/cobi.12571

McClintock BT, Michelot T. 2018. momentuHMM: R package for generalized hidden Markov models of animal movement. Methods in Ecology and Evolution 9(6):1518-1530.

Mitchell LJ, White PC, Arnold KE. 2019. The trade-off between fix rate and tracking duration on estimates of home range size and habitat selection for small vertebrates. PloS One 14(7), e0219357.

Nilsen EB, Pedersen S, Linnell JD. 2008. Can minimum convex polygon home ranges be used to draw biologically meaningful conclusions?. Ecological research 23(3), 635-639.

Noonan MJ, Fleming CH, Tucker MA, Kays R, Harrison A, Crofoot MC, Abrahms B, Alberts SC, Ali AH, Altmann J, Antunes PC, Attias N, Belant JL, Beyer DE, Bidner LR, Blaum N, Boone RB, Caillaud D, Paula RC, la Torre JA, Dekker J, DePerno CS, Farhadinia M, Fennessy J, Fichtel C, Fischer C, Ford A, Goheen JR, Havmøller RW, Hirsch BT, Hurtado C, Isbell LA, Janssen R, Jeltsch F, Kaczensky P, Kaneko Y, Kappeler P, Katna A, Kauffman M, Koch F, Kulkarni A, LaPoint S, Leimgruber P, Macdonald DW, Markham AC, McMahon L, Mertes K, Moorman CE, Morato RG, Moßbrucker AM, Mourão G, O'Connor D, Oliveira-Santos LGR, Pastorini J, Patterson BD, Rachlow J, Ranglack DH, Reid N, Scantlebury DM, Scott DM, Selva N, Sergiel A, Songer M, Songsasen N, Stabach JA, Stacy-Dawes J, Swingen MB, Thompson JJ, Ullmann W, Vanak AT, Thaker M, Wilson JW, Yamazaki K, Yarnell RW, Zieba F, Zwijacz-Kozica T, Fagan WF, Mueller T, Calabrese JM. 2020. Effects of body size on estimation of mammalian area requirements. Conservation Biology:cobi.13495. DOI: 10.1111/cobi.13495.

Ooms J. 2019. pdftools: Text Extraction, Rendering and Converting of PDF Documents.

PeerJ reviewing PDF | (2020:12:56107:2:0:NEW 14 Jun 2021) 
653

654

655

656

657

658

659

660

661

662

663

664

665

666

667

668

669

670

671

672

673

674

675

676

677

678

679

680

681

682

683

684

685

686

687

Parsons ECM. 2016. Why IUCN should replace "Data Deficient" conservation status with a precautionary "Assume Threatened" status - a cetacean case study. Frontiers in Marine Science 3:193. DOI: $10.3389 /$ fmars.2016.00193

Patterson TA, Thomas L, Wilcox C, Ovaskainen O, Matthiopoulos J. 2008. State-space models of individual animal movement. Trends in Ecology and Evolution, 23(2), 87-94. https://doi.org/10.1016/j.tree.2007.10.009

Pebesma E. 2018. Simple Features for R: Standardized Support for Spatial Vector Data. The R Journal.

Pedersen TL, Crameri F. 2018. scico: Colour Palettes Based on the Scientific Colour-Maps.

Piwowar HA, Vision TJ. 2013. Data reuse and the open data citation advantage. PeerJ 1:e175. DOI: $10.7717 /$ peerj. 175 .

Quick, N.J., Cioffi, W.R., Shearer, J. and Read, A.J., 2019. Mind the gap-optimizing satellite tag settings for time series analysis of foraging dives in Cuvier's beaked whales (Ziphius cavirostris). Animal Biotelemetry, 7(1). DOI:10.1186/s40317-019-0167-5

R Core Team. 2020. R: A language and environment for statistical computing. R Foundation for Statistical Computing, Vienna, Austria. URL https://www.R-project.org/.

Refsnider JM, Mitchell TS, Streby HM, Strickland JT, Warner DA, Janzen FJ. 2011. A generalized method to determine detectability of rare and cryptic species using the ornate box turtle as a model. Wildlife Society Bulletin 35(2), 93-100.

Riotte-Lambert L, Matthiopoulos J. 2019. Environmental Predictability as a Cause and Consequence of Animal Movement. Trends in Ecology \& Evolution: S0169534719302885. DOI: 10.1016/j.tree.2019.09.009.

Roche DG, Kruuk LEB, Lanfear R, Binning SA. 2015. Public Data Archiving in Ecology and Evolution: How Well Are We Doing? PLOS Biology 13:e1002295. DOI: 10.1371/journal.pbio.1002295.

Roll U, Feldman A, Novosolov M, Allison A, Bauer AM, Bernard R, Böhm M, Castro-Herrera F, Chirio L, Collen B, Colli GR, Dabool L, Das I, Doan TM, Grismer LL, Hoogmoed M, Itescu Y, Kraus F, LeBreton M, Lewin A, Martins M, Maza E, Meirte D, Nagy ZT, de C. Nogueira C, Pauwels OSG, Pincheira-Donoso D, Powney GD, Sindaco R, Tallowin OJS, Torres-Carvajal O, Trape J-F, Vidan E, Uetz P, Wagner P, Wang Y, Orme CDL, Grenyer R, Meiri S. 2017. The global distribution of tetrapods reveals a need for targeted reptile conservation. Nature Ecology \& Evolution 1:1677-1682. DOI: 10.1038/s41559-017-0332-2.

Ross N. 2020. fasterize: Fast polygon to raster conversion.

Row JR, Blouin-Demers G. 2006. Kernels are not accurate estimators of home-range size for herpetofauna. Copeia 2006(4), 797-802.

RStudio Team (2020). RStudio: Integrated Development for R. RStudio, PBC, Boston, MA URL http://www.rstudio.com/.

Peer) reviewing PDF | (2020:12:56107:2:0:NEW 14 Jun 2021) 
688

689

690

691

692

693

694

695

696

697

698

699

700

701

702

703

704

705

706

707

708

709

710

711

712

713

714

715

716

717

718

719

720

721

722

723

Schipper J, Chanson JS, Chiozza F, Cox NA, Hoffmann M, Katariya V, Lamoreux J, Rodrigues ASL, Stuart SN, Temple HJ, Baillie J, Boitani L, Lacher TE, Mittermeier RA, Smith AT, Absolon D, Aguiar JM, Amori G, Bakkour N, Baldi R, Berridge RJ, Bielby J, Black PA, Blanc JJ, Brooks TM, Burton JA, Butynski TM, Catullo G, Chapman R, Cokeliss Z, Collen B, Conroy J, Cooke JG, da Fonseca GAB, Derocher AE, Dublin HT, Duckworth JW, Emmons L, Emslie RH, FestaBianchet M, Foster M, Foster S, Garshelis DL, Gates C, Gimenez-Dixon M, Gonzalez S, Gonzalez-Maya JF, Good TC, Hammerson G, Hammond PS, Happold D, Happold M, Hare J, Harris RB, Hawkins CE, Haywood M, Heaney LR, Hedges S, Helgen KM, Hilton-Taylor C, Hussain SA, Ishii N, Jefferson TA, Jenkins RKB, Johnston CH, Keith M, Kingdon J, Knox DH, Kovacs KM, Langhammer P, Leus K, Lewison R, Lichtenstein G, Lowry LF, Macavoy Z, Mace GM, Mallon DP, Masi M, McKnight MW, Medellin RA, Medici P, Mills G, Moehlman PD, Molur S, Mora A, Nowell K, Oates JF, Olech W, Oliver WRL, Oprea M, Patterson BD, Perrin WF, Polidoro BA, Pollock C, Powel A, Protas Y, Racey P, Ragle J, Ramani P, Rathbun G, Reeves RR, Reilly SB, Reynolds JE, Rondinini C, Rosell-Ambal RG, Rulli M, Rylands AB, Savini S, Schank CJ, Sechrest W, Self-Sullivan C, Shoemaker A, Sillero-Zubiri C, De Silva N, Smith DE, Srinivasulu C, Stephenson PJ, van Strien N, Talukdar BK, Taylor BL, Timmins R, Tirira DG, Tognelli MF, Tsytsulina K, Veiga LM, Vie J-C, Williamson EA, Wyatt SA, Xie Y, Young BE. 2008. The status of the world's land and marine mammals: diversity, threat, and knowledge. Science 322(5899), 225-230. DOI: 10.1126/science.1165115.

Schneider FD, Fichtmueller D, Gossner MM, Güntsch A, Jochum M, König-Ries B, Le Provost G, Manning P, Ostrowski A, Penone C, Simons NK. 2019. Towards an ecological trait-data standard. Methods in Ecology and Evolution 10:2006-2019. DOI: 10.1111/2041-210X.13288.

Shine R, Madsen T. 1996. Is Thermoregulation Unimportant for Most Reptiles? An Example Using Water Pythons (Liasis fuscus) in Tropical Australia. Physiological Zoology 69:252-269.

Signer J, Fieberg JR. 2021. A fresh look at an old concept: home-range estimation in a tidy world. PeerJ 9:e11031. DOI: 10.7717/peerj.11031

Silva I, Crane M, Marshall BM, Strine CT. 2020. Reptiles on the wrong track? Moving beyond traditional estimators with dynamic Brownian Bridge Movement Models. Movement Ecology 8:1-13.

Slavenko A, Itescu Y, Ihlow F, Meiri S. 2016. Home is where the shell is: predicting turtle home range sizes. Journal of Animal Ecology 85(1), 106-114.

Slowikowski K. 2018. ggrepel: Automatically Position Non-Overlapping Text Labels with "ggplot2."

Smaldino P, O'Connor C. 2020. Interdisciplinarity Can Aid the Spread of Better Methods Between Scientific Communities. OSF Preprints. DOI: 10.31222/osf.io/cm5v3

Smith BJ, Hart KM, Mazzotti FJ, Basille M, Romagosa CM. 2018. Evaluating GPS biologging technology for studying spatial ecology of large constricting snakes. Animal Biotelemetry 6(1), 1.

Stan Development Team. 2020. RStan: the R interface to Stan.

PeerJ reviewing PDF | (2020:12:56107:2:0:NEW 14 Jun 2021) 
724

725

726

727

728

729

730

731

732

733

734

735

736

737

738

739

740

741

742

743

744

745

746

747

748

749

750

751

752

753

754

755

756

757

758

759

760

761

Stattersfield A, Bennun L, Jenkins M. 2004. State of the world's birds: indicators for our changing world. Birdlife International, Cambridge, United Kingdom.

Sung, Y. H., Hau, B., Karraker, N. 2014. Reproduction of endangered Big-headed Turtle, Platysternon megacephalum (Reptilia: Testudines: Platysternidae). Acta Herpetologica 9(2), 243-247. DOI: 10.13128/Acta_Herpetol-14184

Tingley R, Meiri S, Chapple DG. 2016. Addressing knowledge gaps in reptile conservation. Biological Conservation 204:1-5.

Todd BD, Nowakowski AJ. Ectothermy and the macroecology of home range scaling in snakes. Global Ecology and Biogeography 30(1), 262-276.. DOI: https://doi.org/10.1111/geb.13225.

Tucker MA, Böhning-Gaese K, Fagan WF, Fryxell JM, Van Moorter B, Alberts SC, Ali AH, Allen AM, Attias N, Avgar T, Bartlam-Brooks H, Bayarbaatar B, Belant JL, Bertassoni A, Beyer D, Bidner L, van Beest FM, Blake S, Blaum N, Bracis C, Brown D, de Bruyn PJN, Cagnacci F, Calabrese JM, Camilo-Alves C, Chamaillé-Jammes S, Chiaradia A, Davidson SC, Dennis T, DeStefano S, Diefenbach D, Douglas-Hamilton I, Fennessy J, Fichtel C, Fiedler W, Fischer C, Fischhoff I, Fleming CH, Ford AT, Fritz SA, Gehr B, Goheen JR, Gurarie E, Hebblewhite M, Heurich M, Hewison AJM, Hof C, Hurme E, Isbell LA, Janssen R, Jeltsch F, Kaczensky P, Kane A, Kappeler PM, Kauffman M, Kays R, Kimuyu D, Koch F, Kranstauber B, LaPoint S, Leimgruber P, Linnell JDC, López-López P, Markham AC, Mattisson J, Medici EP, Mellone U, Merrill E, de Miranda Mourão G, Morato RG, Morellet N, Morrison TA, Díaz-Muñoz SL, Mysterud A, Nandintsetseg D, Nathan R, Niamir A, Odden J, O’Hara RB, Oliveira-Santos LGR, Olson KA, Patterson BD, Cunha de Paula R, Pedrotti L, Reineking B, Rimmler M, Rogers TL, Rolandsen CM, Rosenberry CS, Rubenstein DI, Safi K, Saïd S, Sapir N, Sawyer H, Schmidt NM, Selva N, Sergiel A, Shiilegdamba E, Silva JP, Singh N, Solberg EJ, Spiegel O, Strand O, Sundaresan S, Ullmann W, Voigt U, Wall J, Wattles D, Wikelski M, Wilmers CC, Wilson JW, Wittemyer G, Zięba F, Zwijacz-Kozica T, Mueller T. 2018. Moving in the Anthropocene: Global reductions in terrestrial mammalian movements. Science 359:466-469. DOI: 10.1126/science.aam9712.

Tucker MA, Alexandrou O, Bierregaard RO, Bildstein KL, Böhning-Gaese K, Bracis C, Brzorad JN, Buechley ER, Cabot D, Calabrese JM, Carrapato C, Chiaradia A, Davenport LC, Davidson SC, Desholm M, DeSorbo CR, Domenech R, Enggist P, Fagan WF, Farwig N, Fiedler W, Fleming CH, Franke A, Fryxell JM, García-Ripollés C, Grémillet D, Griffin LR, Harel R, Kane A, Kays R, Kleyheeg E, Lacy AE, LaPoint S, Limiñana R, López-López P, Maccarone AD, Mellone U, Mojica EK, Nathan R, Newman SH, Noonan MJ, Oppel S, Prostor M, Rees EC, Ropert-Coudert Y, Rösner S, Sapir N, Schabo D, Schmidt M, Schulz H, Shariati M, Shreading A, Paulo Silva J, Skov H, Spiegel O, Takekawa JY, Teitelbaum CS, van Toor ML, Urios V, Vidal-Mateo J, Wang Q, Watts BD, Wikelski M, Wolter K, Žydelis R, Mueller T. 2019. Large birds travel farther in homogeneous environments. Global Ecology and Biogeography 28:576-587. DOI: 10.1111/geb.12875.

Uetz P, Freed P, Hošek J. (2020). Reptile Database. Available at http://www.reptile-database.org

Peer) reviewing PDF | (2020:12:56107:2:0:NEW 14 Jun 2021) 
762 Viana DS, Granados JE, Fandos P, Pérez JM, Cano-Manuel FJ, Burón D, Fandos G, Aguado MÁP, 763 Figuerola J, Soriguer RC. 2018. Linking seasonal home range size with habitat selection and 764 movement in a mountain ungulate. Movement Ecology 6:1. DOI: 10.1186/s40462-017-0119-8.

765 Wickham H. 2007. Reshaping Data with the reshape Package. Journal of Statistical Software 21:1-20.

766 Wickham H. 2016. ggplot2: Elegant graphics for data analysis. Springer-Verlag New York.

767 Wickham H. 2019a. forcats: Tools for Working with Categorical Variables (Factors).

768 Wickham H. 2019b. stringr: Simple, consistent wrappers for common string operations.

769 Wickham H, François R, Henry L, Müller K. 2020. dplyr: A grammar of data manipulation.

770 Wilke CO. 2018. ggridges: Ridgeline Plots in "ggplot2."

771 Wilke CO. 2019. cowplot: Streamlined plot theme and plot annotations for "ggplot2."

772 Worton BJ. 1989. Kernel methods for estimating the utilization distribution in home-range studies.

773 Ecology 70(1), 164-168.

774 Zipkin EF, DiRenzo GV, Ray JM, Rossman S, Lips KR. 2020. Tropical snake diversity collapses after 775 widespread amphibian loss. Science 367(6479), 814-816. 


\section{Table 1 (on next page)}

Scoring category definitions for both number of location and study durations. 
1 Table 1: Scoring category definitions for both number of location and study durations.

\begin{tabular}{|c|c|c|c|c|}
\hline Data Field Type & Score of 0 & Score of 1 & Score of 2 & Score of 3 \\
\hline $\begin{array}{l}\text { Duration } \\
\text { Reproducibility }\end{array}$ & $\begin{array}{l}\text { No reporting - } \\
\text { includes cases } \\
\text { when authors } \\
\text { report at least } \\
\# \# \text { days } \\
\text { without a } \\
\text { maximum }\end{array}$ & $\begin{array}{l}\text { Population-level } \\
\text { reporting- } \\
\text { mean only or } \\
\text { sum of duration } \\
\text { (as number of } \\
\text { days or number } \\
\text { of weeks) }\end{array}$ & $\begin{array}{l}\text { Population-level } \\
\text { reporting - } \\
\text { Mean only or sum } \\
\text { of duration }+ \text { a } \\
\text { metric of spread } \\
\text { (such as standard } \\
\text { deviation or error) }\end{array}$ & $\begin{array}{l}\text { Individual-level } \\
\text { reporting- } \\
\text { actual date ranges } \\
\text { or number of } \\
\text { days for each } \\
\text { individual } \\
\text { included in the } \\
\text { paper. }\end{array}$ \\
\hline $\begin{array}{l}\text { Location } \\
\text { Reproducibility }\end{array}$ & $\begin{array}{l}\text { No reporting - } \\
\text { includes cases } \\
\text { when authors } \\
\text { report at least } \\
\text { \#\# locations } \\
\text { without a } \\
\text { maximum }\end{array}$ & $\begin{array}{l}\text { Population-level } \\
\text { reporting - } \\
\text { mean only or } \\
\text { sum of number } \\
\text { of locations. }\end{array}$ & $\begin{array}{l}\text { Population-level } \\
\text { reporting - } \\
\text { Mean only or sum } \\
\text { of number of } \\
\text { locations }+ \text { a } \\
\text { metric of spread } \\
\text { (such as standard } \\
\text { deviation or error) }\end{array}$ & $\begin{array}{l}\text { Individual-level } \\
\text { reporting- } \\
\text { actual number of } \\
\text { times each } \\
\text { individual was } \\
\text { located during the } \\
\text { study. }\end{array}$ \\
\hline
\end{tabular}




\section{Figure 1}

Reported number of tracks per day.

(A) Density and boxplot plot showing the distribution of all reported tracking frequencies (minimums and maximums), $x$-axis is square-root transformed. Shaded grey area highlights instances of $<1$ track per day. Text labels show the minimum, median, mean, and max numbers of tracks per day. (B) The variation per study between the maximum and minimum tracking frequencies, provided both are $<1$ per day. Both plots exclude all unreported tracking frequencies. 
A

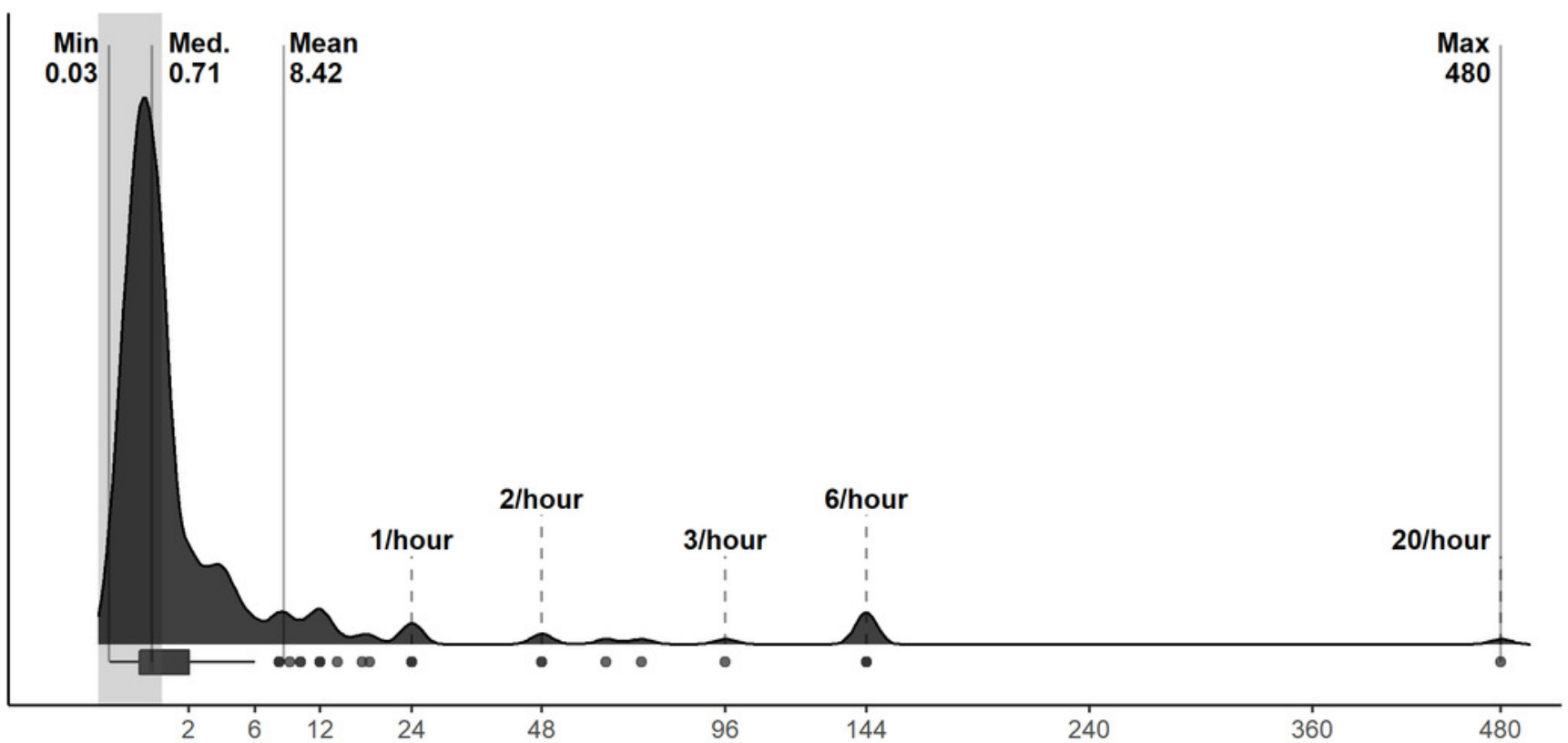

\section{B}

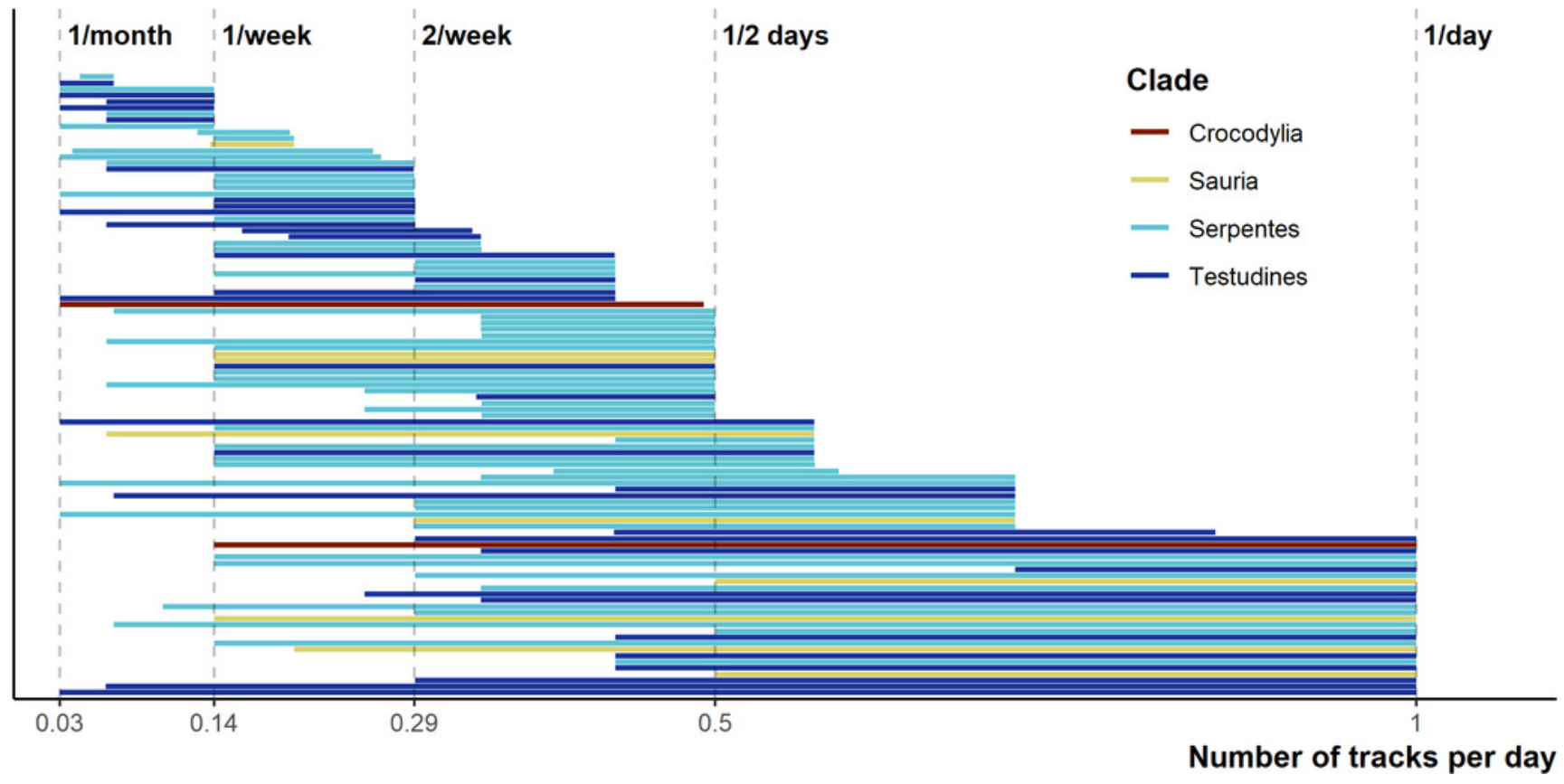




\section{Figure 2}

Reporting scores over time.

(A) whether the study fully reported tracking frequency (complete in blue versus incomplete in red). (B) \% of studies scoring 0 through 3 on location and duration reporting, where a score of 3 is the most complete reporting.

A

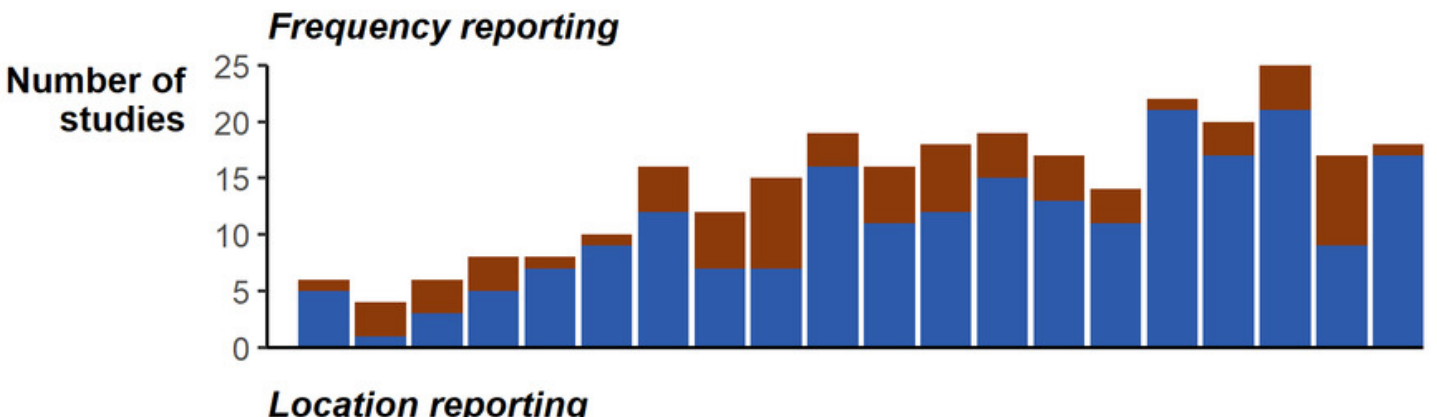

B
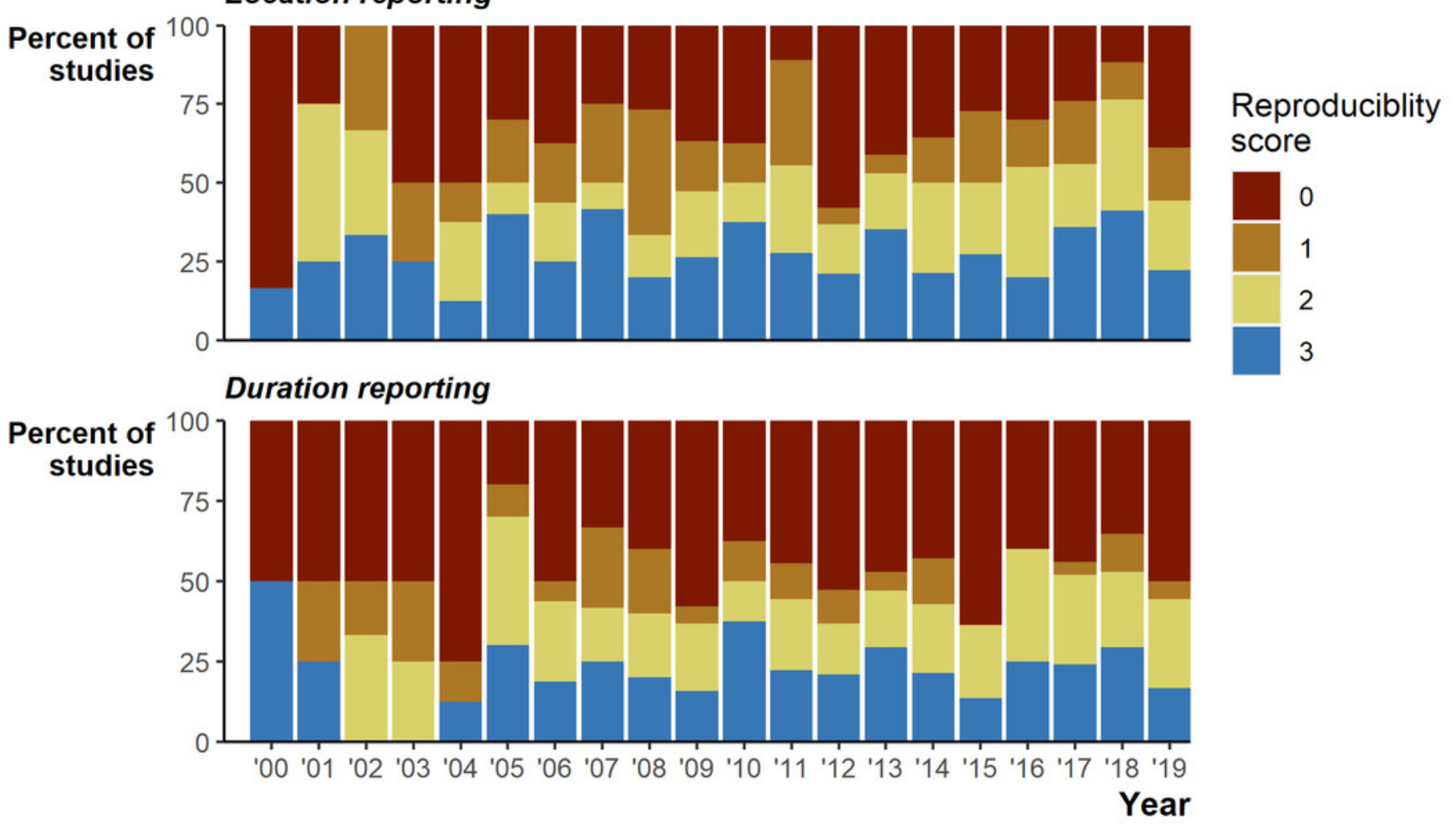


\section{Figure 3}

Changes in the field from 2000 to 2019.

(A) Number of articles over per year and the telemetry devices used: dark grey $=$ only VHF used, middle grey = GPS was used exclusively or in conjunction with VHF, light grey = other device used (ultrasonic and satellite). (B) The percentage of studies using Minimum Convex Polygon (MCP), Kernel Density Estimations (KDE), both or other estimation methods. "Other" only includes studies that did not use either MCPs or KDEs. Lower text labels highlight the year select papers were published aiming to guide, or enable new, space-use estimation.

A

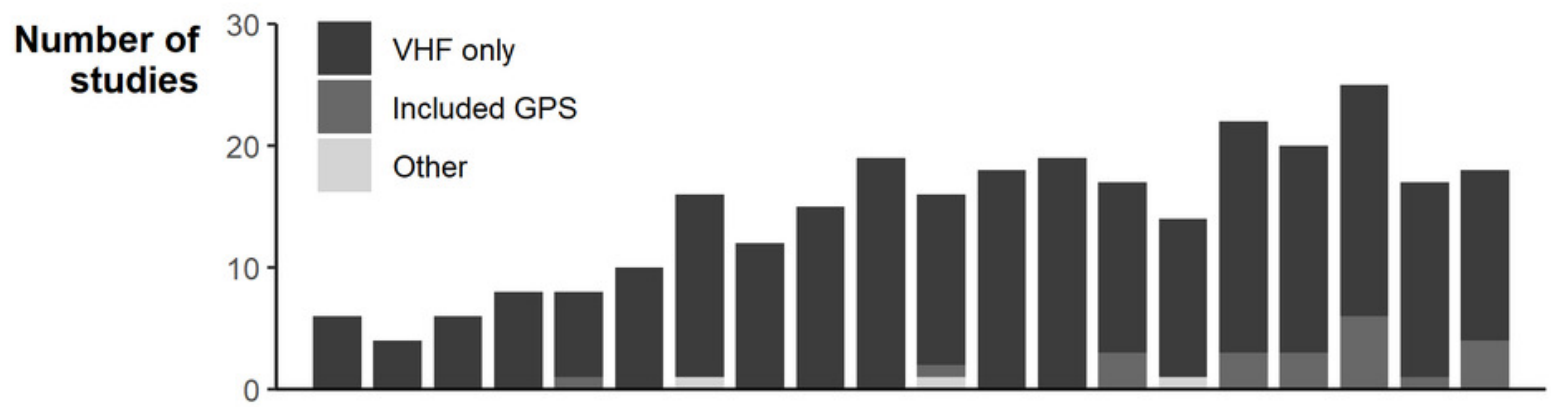

B

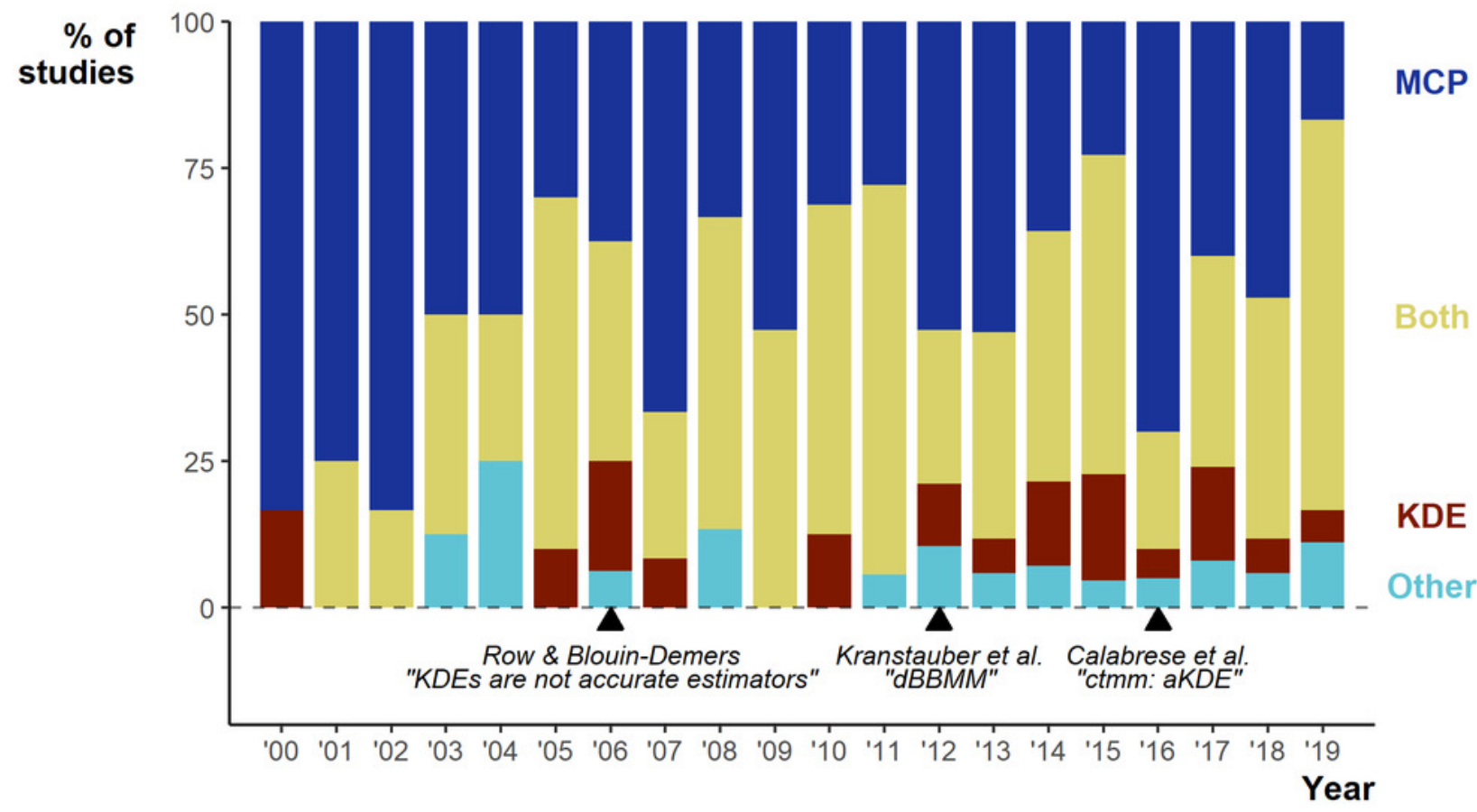




\section{Figure 4}

Number of studies undertaken in each country.

Colour scale is detailed in the insert density plot bottom right [blues indicating more studies, reds indicating fewer studies, grey indicating zero studies], showing the distribution of per country study counts. Count of studies is shown on a log scale to help differentiate between countries with fewer studies, a diverging colour scheme was selected to highlight the highcount outliers. Smaller territories are highlighted with a label denoting the number of studies. Insert map bottom left, shows the distribution of reptile species globally, ranging from zero species (black) to 182 species (yellow); the heatmap was generated using GARD data (Roll et al., 2017).

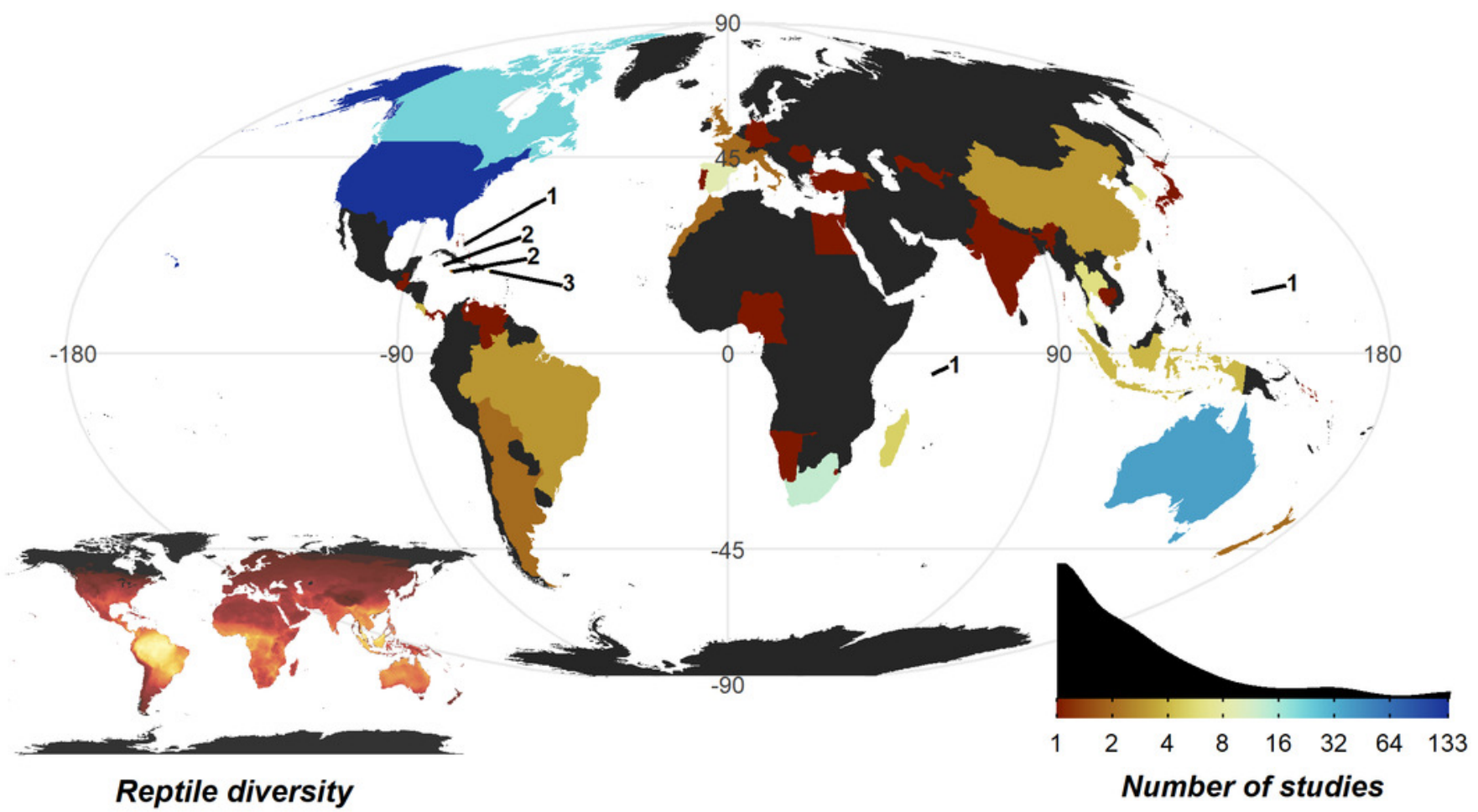


Figure 5

Density and box plots showing the distribution of sample sizes (tracked individuals) per study by clade.

Species names highlight the top two outlying sample sizes for clades other than Crocodylia.

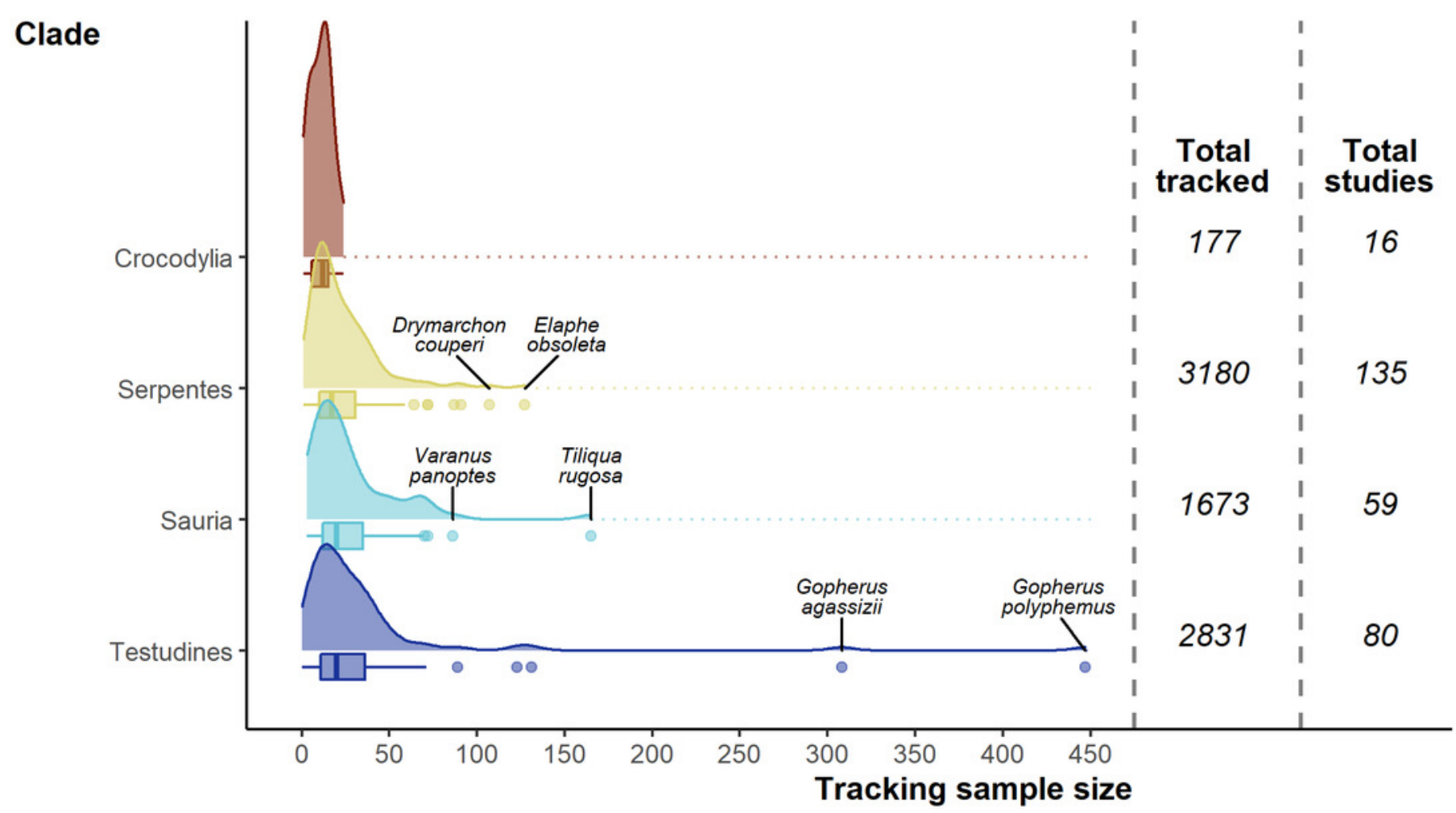


Figure 6

Fitted model values split by group effect of order, flanked top and below by the distribution of studied and unstudied species $\log ^{10}$ body mass (jittered on the y-axis).

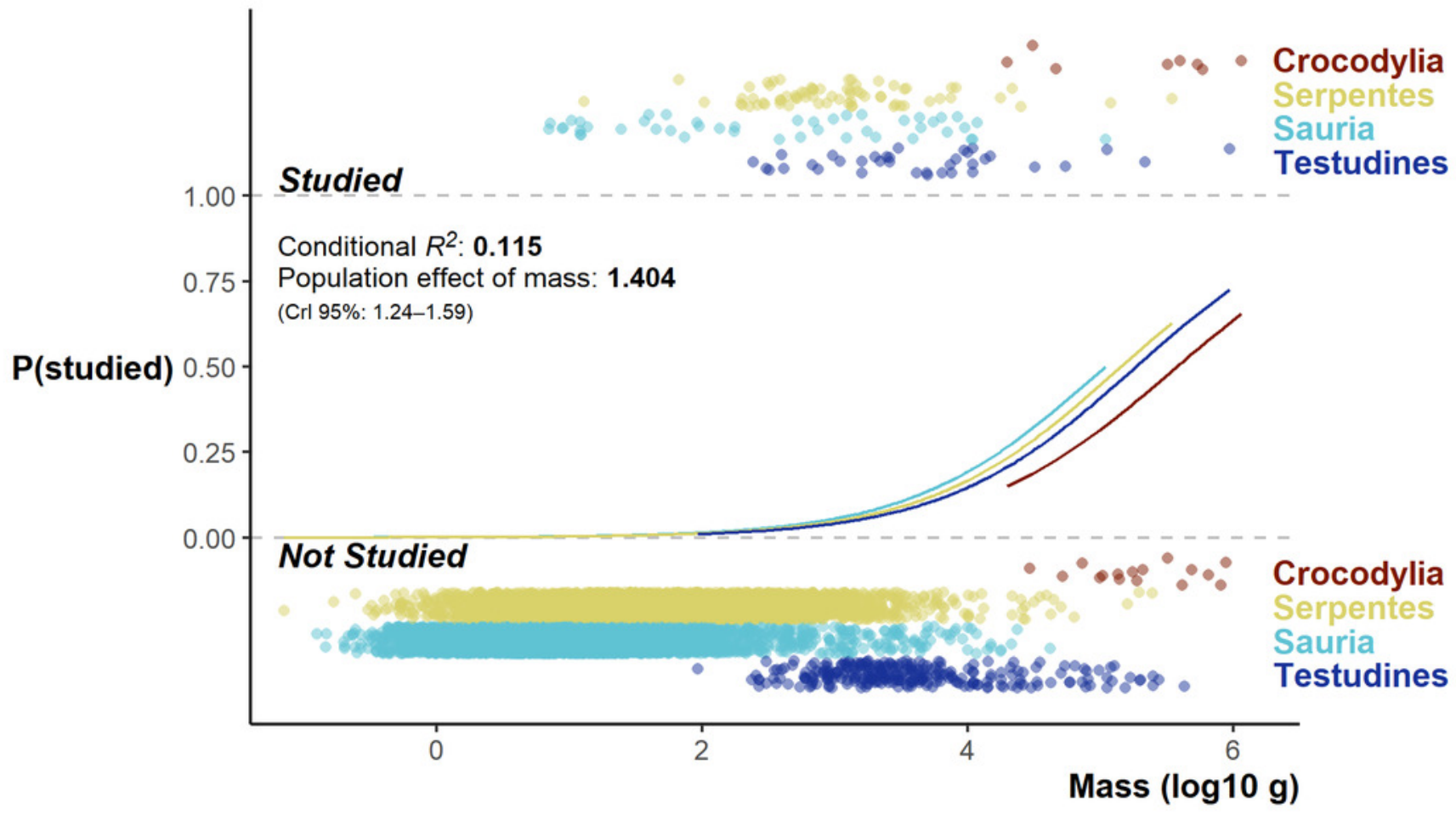




\section{Figure 7}

A breakdown of the two complimentary conceptualisations of animal space-use.

Displayed alongside are examples of the $99 \%$ contour derived from dynamic Brownian Bridge Movement Models (Kranstauber, Smolla \& Scharf, 2016) and autocorrelated Kernel Density Estimators (Calabrese, Fleming \& Gurarie, 2016; Fleming \& Calabrese, 2020). Data used is from Marshall et al. (2020) and can be found in Supp File 4.

\section{What does your space-use} estimate mean?

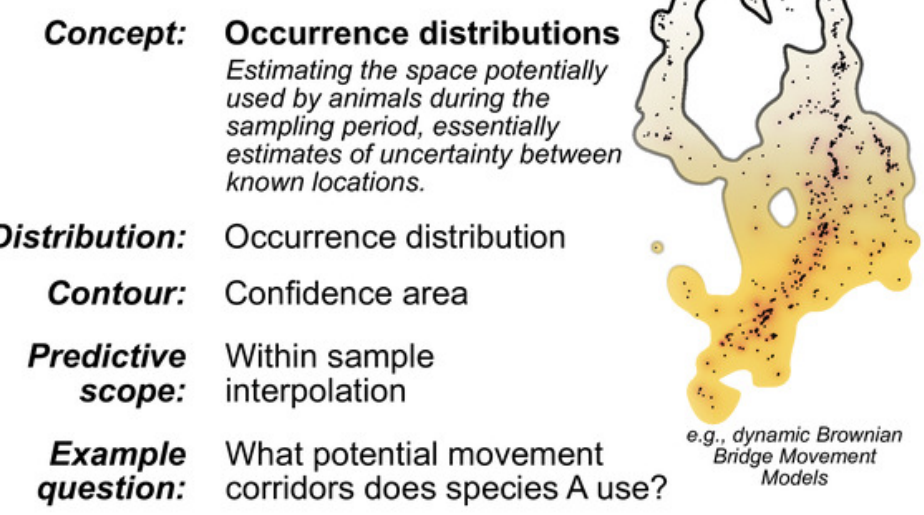

\section{Range distributions}

Estimating the space requirements of animals, corresponding to Burt's 1943 concept of home range.

Utilisation distribution Home range

Beyond sample extrapolation

Does species $A$ have a larger home range than species $B$ ?

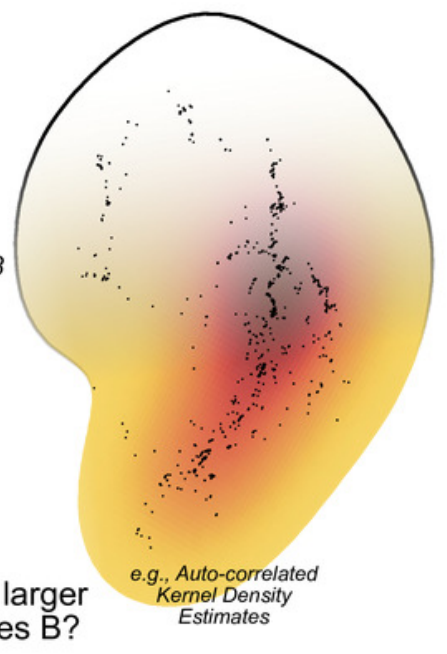

